\title{
Potential Antibiotics for the Treatment of Neonatal Sepsis Caused by Multidrug-Resistant Bacteria
}

\author{
Christopher A. Darlow ${ }^{1}$ (D) Renata M. A. da Costa ${ }^{2}$. Sally Ellis ${ }^{2} \cdot$ François Franceschi $^{2} \cdot$ Mike Sharland $^{3}$. \\ Laura Piddock $^{2,4} \cdot$ Shampa Das $^{1} \cdot$ William Hope ${ }^{1}$
}

Accepted: 4 August 2021 / Published online: 26 August 2021

(c) The Author(s) 2021

\begin{abstract}
Neonatal sepsis causes up to an estimated 680,000 deaths annually worldwide, predominantly in low- and middle-income countries (LMICs). A significant and growing proportion of bacteria causing neonatal sepsis are resistant to multiple antibiotics, including the World Health Organization-recommended empiric neonatal sepsis regimen of ampicillin/gentamicin. The Global Antibiotic Research and Development Partnership is aiming to develop alternative empiric antibiotic regimens that fulfil several criteria: (1) affordable in LMIC settings; (2) activity against neonatal bacterial pathogens, including extendedspectrum $\beta$-lactamase producers, gentamicin-resistant Gram-negative bacteria, and methicillin-resistant Staphylococcus aureus (MRSA); (3) a licence for neonatal use or extensive experience of use in neonates; and (4) minimal toxicities. In this review, we identify five antibiotics that fulfil these criteria: amikacin, tobramycin, fosfomycin, flomoxef, and cefepime. We describe the available characteristics of each in terms of mechanism of action, resistance mechanisms, clinical pharmacokinetics, pharmacodynamics, and toxicity profile. We also identify some knowledge gaps: (1) the neonatal pharmacokinetics of cefepime is reliant on relatively small and limited datasets, and the pharmacokinetics of flomoxef are also reliant on data from a limited demographic range and (2) for all reviewed agents, the pharmacodynamic index and target has not been definitively established for both bactericidal effect and emergence of resistance, with many assumed to have an identical index/ target to similar class molecules. These five agents have the potential to be used in novel combination empiric regimens for neonatal sepsis. However, the data gaps need addressing by pharmacokinetic trials and pharmacodynamic characterisation.
\end{abstract}

Christopher A. Darlow

cdarlow@liverpool.ac.uk

1 Antimicrobial Pharmacodynamics and Therapeutics, Institute of Systems, Molecular and Integrative Biology, University of Liverpool, Liverpool Health Partners, William Henry Duncan Building, 6 West Derby Street, Liverpool L7 8TX, UK

2 Global Antibiotic Research and Development Partnership, Geneva, Switzerland

3 Paediatric Infectious Diseases Research Group, St George's University of London, London, UK

4 Antimicrobials Research Group, Institute for Microbiology and Infection, College of Medical and Dental Sciences, University of Birmingham, Edgbaston, Birmingham, UK

\section{Key Points}

Amikacin, tobramycin, fosfomycin, flomoxef, and cefepime are five safe and off-patent antibiotics with experience of use in neonates that can be potentially used as empiric treatment of neonatal sepsis in low- and middle-income settings where antimicrobial resistance complicates current standard-of-care regimens.

The neonatal pharmacokinetics are well characterised for most, with cefepime and flomoxef needing some additional data.

All agents have data gaps in their pharmacodynamic characterisation in terms of bacterial killing and emergence of resistance 


\section{Introduction}

Over the last few decades, the global neonatal mortality rate has improved, with a fall of $37 \%$ since 1990 [1]. Despite this, neonatal infection continues to contribute to considerable mortality, with neonatal sepsis accounting for $15.6 \%$ of neonatal deaths (an estimated 430,000-680,000 deaths per annum), which predominantly occur in low- and middleincome countries (LMICs) [2-4].

For the past few decades, the World Health Organization (WHO) has recommended a relatively narrow-spectrum $\beta$-lactam (e.g., amoxicillin, benzylpenicillin, or, if at risk of staphylococcal infections, cloxacillin) in combination with gentamicin as first-line empirical treatment of neonatal sepsis, with cefotaxime/ceftriaxone as second line $[5,6]$. The rationale behind this is to provide regimen options that are relatively narrow spectrum, effective against the main causative bacteria (Streptococcus agalactiae, Staphylococcus aureus, and Enterobacterales [7]), have minimal toxicities, and are both inexpensive and practical to administer.

However, as with other bacterial infections, antimicrobial resistance (AMR) is an increasing concern in the treatment of neonatal sepsis [8]. A recent prospective multi-centre epidemiological neonatal sepsis study demonstrated $95 \%$, $80 \%$, and $60 \%$ resistance rates to amoxicillin, ceftriaxone, and gentamicin, respectively, in Gram-negative bacteria causing neonatal sepsis, with widespread carriage of extended-spectrum $\beta$-lactamase (ESBL) genes [9]. Another similar observational neonatal sepsis study in New Delhi [10] presented a similar picture, with over $56 \%$ of causative Gram-negative bacteria resistant to three or more classes of broad-spectrum antibiotics (defined in the study as extendedspectrum cephalosporins, piperacillin-tazobactam, fluoroquinolones, aminoglycosides, and carbapenems), and 38\% of $S$. aureus infections were methicillin resistant. These observed resistance patterns have been replicated in other regional retrospective observational studies [11-16]. With such high rates of $\beta$-lactam and gentamicin resistance, it is increasingly clear that the current WHO-recommended regimen for neonatal sepsis is no longer optimal in the context of neonatal sepsis, and so an alternative first-line empiric regimen is needed.

Such a regimen should have activity against the main causative bacteria and resistance motifs and be suitable for use in an LMIC setting. Although newly developed agents may have the required spectrum of activity, they are unlikely to be available in the near future because of licensing and cost limitations and the well-recognised delay in obtaining a paediatric and neonatal licence (which can be up to 10 years after the adult licence) [17]. However, a number of older off-patent antimicrobials retain the requisite spectrum of antimicrobial activity and could be repurposed for use in neonatal sepsis.

The identification of new antimicrobial regimens for treatment of neonatal sepsis is one of the goals of the Global Antibiotic Research and Development Partnership (GARDP). In particular, the GARDP aims to develop an antimicrobial regimen for use in LMICs for the empiric treatment of neonatal sepsis in locations with increasing resistance to current WHO-recommended treatments [18].

Criteria were developed for selecting antimicrobial agents that fulfilled the needs of such a treatment (Table 1) [18]. These criteria were applied to a list of antibiotics extracted from Kucers' [19], supplemented by additional agents licensed by the European Medicines Agency/US FDA after 2017. Five agents fulfilled these criteria and were identified as candidates with potential utility (either alone or in combination) for the treatment of neonatal sepsis in LMIC settings: amikacin, tobramycin, fosfomycin, flomoxef, and cefepime. This review examines the pharmacological characteristics of each, with a focus on neonatal use.

\section{Literature Review Methodology}

The literature was reviewed for each component of the review by searching MEDLINE (via PubMed) with the following general search term strategy: [antibiotic name $]+$ [pharmacological characteristic $] \pm$ [demographic qualifier]. For the term [antibiotic name], individual antibiotic names were used, along with development names (e.g., 6513-S for flomoxef) where known. For the term [pharmacological characteristic], broad terms were used for the domain of interest, with further narrower terms for specific components. For example, 'toxicity' was used for a broad initial search for the toxicity characteristics of each drug, with subsequent narrower search terms for specific identified toxicities (e.g., 'nephrotoxicity' for the aminoglycosides). A similar search term strategy (i.e., an initial broad search

Table 1 Criteria for selection of candidate antibiotics for treatment of neonatal sepsis in low- and middle-income countries [18]

Criteria for antimicrobial selection

1. Antimicrobial should be inexpensive to manufacture (i.e., off patent)

2. Clinically relevant activity against multidrug-resistant bacteria, particularly Gram-negative bacteria with gentamicin resistance or extended-spectrum $\beta$-lactamases and methicillin-resistant Grampositive organisms

3. Licensed for use in neonatal infection by a stringent regulatory authority (e.g., the European Medicines Agency); or extensive experience of use in the neonatal context where no licence

4. Limited toxicity 
term, with subsequent narrower search terms for components specific to each domain) was used for each pharmacological section (e.g., clinical pharmacokinetics, resistance mechanisms, pharmacodynamics, etc.).

These searches were performed with and without the [demographic qualifier] term for relevant pharmacological characteristics (i.e., toxicity, clinical pharmacokinetics) using the terms 'neonate', 'neonatal', and 'infant' to capture and identify published data in the neonatal age group, where these were available.

Literature retrieved by the searches was screened for relevance. The primary author extracted data for incorporation into the manuscript, and the senior authors provided expert critical review and feedback.

\section{Amikacin and Tobramycin}

Amikacin and tobramycin are aminoglycosides with in vitro activity against gentamicin-resistant bacteria. Aminoglycosides consist of a central dibasic aminocyclitol core (usually 2-deoxystreptamine) with one or two amino sugar moieties connected via glycosidic links [20]. Resistance to firstgeneration aminoglycosides (e.g., kanamycin, gentamicin) became widespread with their use in clinical practice, with resistance largely caused by aminoglycoside-modifying enzymes (AMEs) [21]. Later-generation aminoglycosides have properties that circumvent some AMEs, increasing their clinical usefulness in infections caused by isolates resistant to first-generation aminoglycosides.

Amikacin is a semi-synthetic aminoglycoside derived from kanamycin by the addition of an L- $(-)-\gamma$-amino- $\alpha$ hydrobutyryl side chain to the 2-deoxystreptamine component of the molecule [22] (Fig. 1). This additional side chain interferes with the binding of many AMEs, which otherwise inactivate many other aminoglycosides, extending the activity of amikacin to most gentamicin-resistant bacteria.

Tobramycin is a naturally occurring aminoglycoside isolated from Streptomyces tenebrarius and is structurally similar to kanamycin and gentamicin C1a [23]. Compared with the latter, tobramycin has a 3-amino-3-deoxyglucose instead of a 3-deoxy-3-methylamino-4-C-methylxylose (Fig. 1). Tobramycin was developed because of its increased<smiles>NCC[C@H](O)C(=O)N[C@H]1C[C@@H](N)[C@H](O[C@H]2O[C@H](CN)[C@@H](O)[C@H](O)[C@H]2O)[C@H](O)[C@H]1O[C@@H]1O[C@H](CO)[C@@H](O)[C@H](N)[C@H]1O</smiles>

A

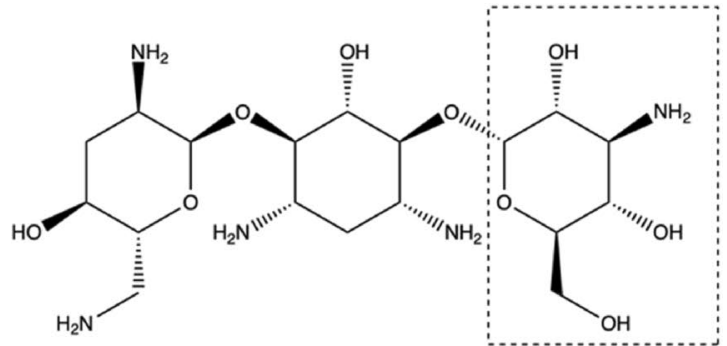

B<smiles>NC[C@H]1O[C@H](C[C@@H]2[C@@H](N)C[C@@H](N)[C@H](O[C@@H]3O[C@H](CO)[C@@H](O)[C@H](N)[C@H]3O)[C@H]2O)[C@H](O)[C@H](O)[C@@H]1O</smiles>

Kanamycin

\section{Tobramycin}<smiles>CN[C@H]1[C@@H](O)[C@@H](O[C@@H]2[C@@H](N)C[C@@H](N)[C@H](O[C@@H]3O[C@H](CN)CC[C@H]3N)[C@H]2O)OC[C@]1(C)O</smiles>

Gentamicin C1a

Fig. 1 Chemical structures of amikacin and tobramycin, with comparator molecules of kanamycin and gentamicin C1a. (A) L-(-)- $\gamma$-amino- $\alpha$ hydrobutyryl side chain, (B) 3-amino-3-deoxyglucose 
activity against Pseudomonas aeruginosa compared with pre-existing aminoglycosides [24].

\subsection{Mechanism of Action}

Tobramycin and amikacin inhibit protein synthesis by binding to the $30 \mathrm{~S}$ bacterial ribosome subunit, causing mistranslation of bacterial proteins. Specifically, they bind to the aminoacyl-transfer RNA recognition site of the $16 \mathrm{~S}$ ribosomal RNA (rRNA) component of the 30S ribosome [20, 25]. Entry to the bacterial cell is via the "self-promoted uptake pathway'. Both agents are polycationic and must initially bind to anionic compounds, e.g., lipopolysaccharides in Gram-negative bacteria and teichoic acids and phospholipids in Gram-positive bacteria. This binding increases the permeability of the outer membrane, allowing penetration of the antibiotic into the periplasmic space [26]. Following this, an energy-dependent uptake process provides access to the cytoplasm [27], where it can engage with the ribosomal target. Protein mistranslation caused by ribosomal binding further increases membrane permeability, allowing further entry of the aminoglycoside into the cytoplasm and leading to further bactericidal effect.

As with other aminoglycosides, both agents have a spectrum of activity against Gram-negative bacteria, including $P$. aeruginosa [20]. Aminoglycosides also have activity against staphylococci but are largely ineffective against other Grampositive bacteria as monotherapy. The need to use the active electron transport process to enter the bacterial cell means anaerobic bacteria are intrinsically resistant [20].

\subsection{Resistance Mechanisms}

Resistance to amikacin and tobramycin, like other aminoglycosides, occurs by one of the five following mechanisms.

\subsubsection{Inactivation by Aminoglycoside-Modifying Enzymes}

AMEs act by modifying specific hydroxyl or amino groups on either the 2-deoxystreptamine nucleus or the sugar moieties. There are three main types: acetyltransferases (AACs), nucleotidyltransferases (ANTs), and phosphotransferases (APHs). Individual AMEs are named as the acronym of their type, with the site of enzymatic modification within parenthesis, e.g., AAC $\left(2^{\prime}\right)$. Subsequent roman numerals refer to the resistance profile they confer, with further lower-case letters as individual identifiers [28].

A large number of AMEs have been identified [21], encoded on transmissible elements (e.g., plasmids), transposons, and bacterial chromosomes. Aminoglycoside susceptibility to individual AMEs is linked to the specific configuration of their side chains.
Amikacin is refractory to inactivation by most AMEs because of its amino- $\alpha$-hydrobutyryl side chain. However, multiple AMEs with activity against amikacin have emerged, mostly by acetylation of $6^{\prime}-\mathrm{N}$ position. These AAC $\left(6^{\prime}\right)$ enzymes have activity against amikacin but not normally gentamicin [21].

Tobramycin is resistant to the $\mathrm{AAC}(1), \mathrm{AAD}\left(4^{\prime}\right)$, and $\operatorname{APH}\left(2^{\prime \prime}\right)$ enzymes that inactivate gentamicin. However, several enzymes confer cross-resistance to both gentamicin and tobramycin (but not amikacin), including $\mathrm{AAC}(2), \mathrm{AAC}(3)$, $\operatorname{AAC}\left(2^{\prime}\right), \operatorname{AAC}\left(6^{\prime}\right)$, and $\operatorname{AAD}\left(2^{\prime \prime}\right)$. Additionally $\operatorname{AAD}\left(4^{\prime}\right)$ deactivates tobramycin but not gentamicin [25].

Although AMEs usually have limited cross-reactivity between aminoglycosides, bacteria can accumulate multiple AME genes, conferring pan-aminoglycoside resistance.

\subsubsection{Modification of Target Site by 16S Methylation}

Post-transcriptional methylation of the $16 \mathrm{~S}$ rRNA subunit inhibits the binding of aminoglycosides to the ribosome. It is commonly observed in aminoglycoside-producing Actinobacteria to provide autoprotection against endogenous aminoglycoside production [29]. However, nine plasmidmediated 16S rRNA methyltransferases have been identified in non-Actinobacteria species: ArmA, RmtA-H, and NpmA [29]. These enzymes give high-level resistance to all 4,6-disubstituted 2-deoxystreptamine aminoglycosides (which include gentamicin, tobramycin, and amikacin) as well as newer aminoglycosides [30]. The spread of plasmidmediated 16S rRNA methylases in Gram-negative bacteria is of particular concern because they also usually carry genes that encode ESBLs and carbapenemases [31].

\subsubsection{Target Site Modification}

Chromosomal mutation of the $16 \mathrm{~S}$ rRNA gene in Mycobacterium tuberculosis confers resistance to kanamycin [32] and streptomycin [33]. Mutations conferring resistance to amikacin have been reported in atypical mycobacteria [34]. To date, no chromosomal 16S rRNA gene mutation has been reported in non-mycobacterial bacteria.

\subsubsection{Alteration of Uptake Mechanisms}

Given the complexity of aminoglycoside uptake into Gram-negative bacteria, resistance mediated by changes to self-promoted uptake is poorly understood. There is little evidence for porin involvement in uptake, and specific mutations in porin genes conferring clinically relevant levels of resistance have not been described [35]. Disruption of uptake into cells is thought to also be a mechanism of resistance in staphylococci [36]. 


\subsubsection{Enhanced Drug Efflux}

A wide range of bacterial efflux pumps have been characterised [37, 38]. Some pumps export aminoglycosides; for example, $P$. aeruginosa-expressing MexXY pumps have been associated with amikacin resistance [39].

\subsection{Clinical Pharmacokinetics}

Like other aminoglycosides, amikacin and tobramycin have poor oral bioavailability, requiring parenteral administration. Peak plasma concentration $\left(C_{\max }\right)$ occurs approximately 30 min post-infusion for both drugs in adults and neonates [40-43].

Both drugs are strongly hydrophilic and distribute primarily into extracellular fluid with a volume of distribution $\left(V_{\mathrm{d}}\right)$ of $0.5-0.6 \mathrm{~L} / \mathrm{kg}$ in neonates for both agents $[44,45]$. Aminoglycosides do not significantly penetrate the cerebrospinal fluid (CSF) in adults [46], even when the meninges are inflamed. However, in neonates, a CSF partition coefficient of 0.103 for amikacin has been estimated [47], although there is limited evidence of drug penetration with tobramycin [48] (for comparison, gentamicin penetrance is negligible $[49,50])$. Protein binding is minimal for both drugs $[51,52]$.

Amikacin and tobramycin are renally excreted unmetabolised. The adult elimination half-life is $\sim 2 \mathrm{~h}$ for both agents, with $>90 \%$ of drug recovered from urine within $24 \mathrm{~h}$ [51, 53]. However, the terminal elimination phase after cessation of therapy is prolonged, with $100 \%$ renal excretion requiring 10-20 days for both drugs [51, 54]. In neonates, the halflife can be significantly longer because of renal ontogenesis: $7.6 \pm 4.4 \mathrm{~h}$ for amikacin [55] and 2-7.3 $\mathrm{h}$ for tobramycin [43].

Renal tubular accumulation of aminoglycosides, mediated by several transporters [56], is thought to be the mechanism of nephrotoxicity and the prolonged terminal phase of elimination. Identified transporters include Megalin, Cubilin, TRPV1, and TRPV4 [57-60]; all have affinity for most aminoglycosides, but the relative affinity varies between individual molecules, likely reflecting the variable nephrotoxicity of different aminoglycosides.

\subsection{Toxicity}

There are three main aminoglycoside toxicities. First, aminoglycoside use can cause a reversible non-oliguric renal impairment due to aminoglycoside accumulation in proximal tubular epithelial cells, leading to tubular necrosis [61]. Once-daily dosing in adults reduces this toxicity compared with multiple daily dosing [62], implying a time above plasma concentration threshold relationship for nephrotoxicity (in contrast to a peak concentration relationship for bacterial killing). Comparable data are scarce in neonates $[63,64]$, although the relationship to dosing schedule is presumed to be consistent between age groups, leading to predominant use of once-daily dosing in neonates [65-67].

Aminoglycosides can cause ototoxicity via damage to the sensory hair cells of the inner ear, particularly the highfrequency outer hair cells [68]. This can produce irreversible cochlear function impairment. Vestibular impairment can also occur, but this is reversible on cessation of the drug. The exact mechanism is not understood; the dose-effect relationship seems to be idiosyncratic and possibly associated with certain mitochondrial genetic variations $[68,69]$. Detailed neonatal data are absent, but neonatal amikacin use may be associated with a 3\% ototoxicity incidence [63]. Tobramycin does not appear to be associated with significant ototoxicity [70].

Neuro-muscular blockade is a rare but serious toxicity associated with aminoglycoside use. However, cases have only been reported in adults [71-73]; there have been no reported cases in neonates.

\subsection{Pharmacodynamics}

Specific pharmacodynamic targets for tobramycin and amikacin have not been established. However, there are considerable published in vitro and in vivo pharmacodynamic data for other aminoglycosides.

Multiple aminoglycoside dose fractionation studies in neutropenic mouse models [74-77] suggest that the pharmacodynamic index that best links drug exposure with antimicrobial activity is $C_{\max } /$ minimum inhibitory concentration (MIC). However, other experimental platforms suggest the relevant pharmacodynamic index is area under the concentration-time curve (AUC)/MIC [78, 79].

In multiple adult clinical trials, the $C_{\max } / \mathrm{MIC}$ ratio has repeatedly been related to clinical success of aminoglycosides [80-85], with a pharmacodynamic target of $C_{\max } / \mathrm{MIC}$ $\geq 10$ for a $>90 \%$ successful clinical outcome where this was calculated [80, 84]. Interestingly, where the AUC/MIC was also calculated, it was equally related with patient outcomes $[84,85]$.

Because of the limited human dosing schedules of aminoglycosides (once daily in most published trials), $C_{\max }$ and AUC are co-linear [86], a likely reason for the inability to distinguish $C_{\max } / \mathrm{MIC}$ and AUC/MIC as the relevant pharmacodynamic index. Therefore, pragmatically, $C_{\max }$ (rather than AUC) is used in therapeutic drug monitoring in clinical contexts $[84,86]$.

\subsection{Potential Utility in Neonatal Sepsis}

Both aminoglycosides have potential utility in neonatal sepsis given their spectra of activity against Gram-negative 
bacteria that are gentamicin resistant and staphylococci. Given its stability to a wider range of AMEs, amikacin is the more promising choice in an AME-prevalent environment. Both agents would rely on another antibiotic in a potential combination regimen to provide activity against streptococci.

Both aminoglycosides have a long history of neonatal use, with pharmacokinetics and pharmacodynamics well understood. Although toxicities are associated with their use, they can be mitigated.

\section{Fosfomycin}

Fosfomycin is a phosphoric acid derivative isolated from various Streptomyces species [87]. Fosfomycin is a small molecule (Fig. 2), with a molecular weight of $138 \mathrm{~g} / \mathrm{mol}$ [88] and three different formulations: a disodium compound, used for intravenous administration, and tromethamine and calcium compounds, used for oral administration. The following discussion is focused on the disodium formulation given the typical requirement for parenteral treatment of neonates.

\subsection{Mechanism of Action}

Fosfomycin inhibits the enzyme MurA, which catalyses the reaction of UDP- $N$-acetylglucosamine (UDP-GlcNAc) with phosphoenolpyruvate (PEP) to form UDP-GlcNAcenolpyruvate plus inorganic phosphate [89]. Specifically, fosfomycin acts as a PEP analogue to inhibit the enzyme [90]. This reaction is the first step in peptidoglycan synthesis, with inhibition of this process inhibiting bacterial cell wall synthesis, leading to cell death.

Uptake of fosfomycin into the bacterium is dependent on two bacterial transporters. The first, GlpT, is an antiporter that normally transports glycerol-3-phosphate (G3P) in exchange for a phosphate molecule [91]. This uptake system is found amongst many species of bacteria [90].

Alternatively, the hexose-phosphate uptake system (UhpT) can also transport fosfomycin. This mechanism is glucose-6-phosphate (G6P) dependent and limited to Enterobacterales (with the exception of Proteus species) and $S$. aureus species [92]. This transporter is only induced in the presence of G6P, so fosfomycin uptake via this pathway

Fig. 2 Molecular structure of fosfomycin. A oxirane ring usually requires the presence of G6P. As a result, in vitro assays involving fosfomycin require G6P supplementation.

Fosfomycin has a broad spectrum of activity, with potential activity against most Gram-positive and Gram-negative bacteria, including Pseudomonas species and anaerobes [93], with Acinetobacter and Listeria species being important exceptions [89, 94].

\subsection{Resistance Mechanisms}

There are three main resistance mechanisms against fosfomycin.

\subsubsection{Reduced Permeability to Fosfomycin}

Fosfomycin uptake is dependent on the presence of either GlpT or UhpT transporters. Mutations in the genes encoding either can confer resistance. Species that lack both transporters (e.g., Listeria monocytogenes) are inhibited by intrinsically higher fosfomycin MICs [94, 95]. Some species intrinsically lack one pathway, with development of resistance requiring only a single gene mutation, e.g., $g l p T$ in the UhpT-lacking $P$. aeruginosa.

Both transport systems are cyclic adenosine monophosphate (cAMP) dependent. Therefore, mutations that reduce cAMP levels (e.g., ptsl or cyaA mutations) will prevent cell penetration of fosfomycin [96, 97], albeit at a survival cost due to alterations in carbohydrate catabolism. This survival cost may explain the discrepancy between the high rate of resistance $\left(>10^{-2}\right)$ observed in vitro and the rare occurrence of fosfomycin-resistant clinical isolates where fosfomycin use is prevalent [98].

\subsubsection{Modification of MurA Target}

Mutations of the murA gene encoding the target MurA protein can occur. In vitro mutagenesis of MurA altering Cys 115 to Asp confers resistance [99], but this has not been seen in clinical isolates. A number of other mutations in murA (Asp369Asn, Leu370Ile, Asp3890Ala, Gln59Lys, GIU139Lys, Val389Ile) have been identified in fosfomycinresistant clinical samples [100-102], but these mutations are infrequent compared with other resistance mechanisms. Interestingly, in vitro overexpression of $m u r A$ also increases the fosfomycin MIC [103], although this mechanism has not been identified in clinical isolates.

\subsubsection{Modification by Fosfomycin-Modifying Enzymes}

Fosfomycin-modifying enzymes are the most frequently identified cause of resistance in clinical isolates, with three metalloenzymes identified: FosA, FosB, and FosX. All modify the fosfomycin molecule by opening the oxirane ring of 
the fosfomycin molecule (Fig. 2), using different substrates to add chemical groups to the molecule:

- FosA is a $\mathrm{Mn}^{2+}$ - and $\mathrm{K}^{+}$-dependent glutathione-S-transferase, originally identified on a plasmid in a Serratia marcescens strain [104, 105]. FosA-type enzymes have been identified in multiple different clinically resistant isolates [101] and are often co-expressed with other AMR genes (e.g., $b l a_{\mathrm{KPC}}$ and $b l a_{\mathrm{CTX}-\mathrm{M}}$ ) in some geographic regions [106, 107]. fosA homologues have also been identified in the chromosome of many Gram-negative bacteria strains, including Klebsiella, Enterobacter, Serratia, and Pseudomonas species [108, 109].

- FosB is a $\mathrm{Mg}^{2+}$-dependent thiol-S-transferase, originally identified in Staphylococcus epidermidis [110] but found in many other low G+C Gram-positive bacteria (e.g., Bacillus species and $S$. aureus) that do not synthesise glutathione. This is the most prevalent fosfomycin-resistance mechanism in S. aureus [111].

- FosX is a $\mathrm{Mn}^{2+}$-dependent epoxide hydrolase that uses water to hydrolyse the oxirane ring. The fos $X$ gene has been identified in the chromosomes of several species, including L. monocytogenes [112].

In addition, there are two fosfomycin kinases: FomA and FomB. These sequentially add phosphate groups to the phosphonate moiety of fosfomycin from adenosine triphosphate with $\mathrm{Mg}^{2+}$ as a cofactor [113]. These have only been found in fosfomycin-producing Streptomyces species, providing autoprotection to these bacteria.

\subsection{Clinical Pharmacokinetics}

Given its small molecular weight, fosfomycin distributes widely into most tissues, including bone and soft tissue [114, 115], with an adult $V_{\mathrm{d}}$ of 9-30 L [116], and protein binding is negligible [117]. CSF penetration is partial, with a partition coefficient of $\sim 0.15-0.2$ in adults [118] and 0.32 in neonates [119]. Fosfomycin is almost entirely cleared by renal excretion, with $\sim 90 \%$ of the drug recovered unchanged in the urine by $48 \mathrm{~h}[120,121]$ and an adult half-life of 1.9-3.9 $\mathrm{h}$ [116]. Fosfomycin is not metabolised. Significant levels of fosfomycin have been detected in the bile [116, 122], suggesting that biliary excretion accounts for the remaining clearance. However, as studies measuring faecal fosfomycin levels used incompletely bioavailable oral formulations, this has yet to be confirmed.

A recent fosfomycin pharmacokinetic study in neonates ( $n=61$ ) examining $100 \mathrm{mg} / \mathrm{kg}$ bolus doses gave a median $C_{\max }$ of approximately $350 \mathrm{mg} / \mathrm{L}$ (with large inter-individual variability) with a median $\beta$-phase half-life of $5.2 \mathrm{~h}$ [119]. This is concordant with the limited published pharmacokinetic data in neonates, with two small pharmacokinetic studies (total $n=22$ ) giving $C_{\max }$ values of $\sim 96-98 \mathrm{mg} / \mathrm{L}$ and $\sim 135 \mathrm{mg} / \mathrm{L}$ following $50 \mathrm{mg} / \mathrm{kg}$ intravenous bolus and $200 \mathrm{mg} / \mathrm{kg}$ infusion (30-120 min), respectively, and a mean half-life of $\sim 7 \mathrm{~h}$, with a half-life of $4.9 \mathrm{~h}$ in a subset of older neonates (3-4 weeks old; $n=6$ ) [123, 124].

\subsection{Toxicity}

Fosfomycin is associated with no common serious adverse events and limited common adverse events, most notably hypokalaemia [125]. Phlebitis, rash, and gastrointestinal upset occur commonly but are no more frequent than with comparator antibiotics. There is potential concern about the inherent sodium load with intravenous fosfomycin disodium administration, with adverse outcomes related to sodium overload noted in two recent adult trials, both involving cardiac patients at risk of overload and prolonged parental treatment $[126,127]$. This may be relevant to neonates given their risk of fluid overload [128], but such adverse events have yet to be demonstrated in this context.

\subsection{Pharmacodynamics}

Studies examining the most relevant pharmacodynamic index for fosfomycin have yielded conflicting results. Different animal models have identified the relevant pharmacodynamic index as $C_{\max }$ MIC [129] or AUC/MIC (with ratios of 23 and 83 required for stasis and 1-log kill in Enterobacterales, respectively) [130], and an in vitro dynamic onecompartment experiment assessing $P$. aeruginosa suggested \%time $>$ MIC is the relevant index [131] (although the possibility of AUC/MIC as the index was not assessed). Several other non-dynamic in vitro studies have come to different conclusions about the index for bacterial kill $[118,132$, 133], but it is difficult to give weight to these conclusions over those from dynamic models. With regards to emergence of resistance, a single hollow fibre infection model experiment suggested that the AUC/MIC ratio is the relevant pharmacodynamic index [134].

\subsection{Potential Utility in Neonatal Sepsis}

Fosfomycin has been underused since its discovery in the 1960s, despite its broad spectrum of activity, and it has activity against most neonatal sepsis pathogens. Additionally, its unique mechanism of action limits potential crossresistance from other antimicrobial classes. These factors mean that fosfomycin-resistance rates are low globally and make this agent suitable for treatment of neonatal sepsis in AMR-prevalent settings [128].

Previous data gaps in neonatal pharmacokinetics have largely been answered by the recent large NeoFOSFO pharmacokinetic study [119]. However, the pharmacodynamic 
characterisation of fosfomycin is incomplete, with the exact pharmacodynamic indices uncertain. Finally, regulatory approval for fosfomycin is not universal, with a licence not yet available in many LMICs.

\section{Flomoxef}

Flomoxef is an oxacephem class $\beta$-lactam antibiotic first synthesised in Japan in the 1980s [135, 136]. $\beta$-lactams are amongst the most widely used class of antibiotic globally $[137,138]$, characterised molecularly by a common $\beta$-lactam ring [137]. The predominant mechanism of $\beta$-lactam resistance is degradation by $\beta$-lactamases, with increasing prevalent ESBLs being a significant cause of $\beta$-lactam resistance globally [139].

Oxacephems are derivatives of cephalosporins, originally isolated from Streptomyces species [135]. The molecular configuration of oxacephem sidechains confer particular activity against Gram-negative bacteria and stability against degradation by $\beta$-lactamases [140], albeit normally at the expense of activity against Gram-positive bacteria [141].

However, flomoxef has an additional 7- $\beta$-difluoromethylthioacetamido side chain substitution that enables high levels of activity against both Gram-positive and Gram-negative bacteria (including anaerobes) and a reduced toxicity profile [142, 143] (Fig. 3). Additionally, the $N$-methyltetrazolethiol (NMTT) group attached to the 3 '-position of the oxacephem nucleus (thought to be responsible for the disulfiram- and coumarin-like side effects seen in NMTT-containing oxacephems, e.g., latamoxef) is substituted with a methylthiadiazolethiol (MTDT) group [144, 145].

Despite the benefits of this molecule over other $\beta$-lactams and its widespread use in Japan [136], flomoxef is currently licensed and used only in East Asia.

\subsection{Mechanism of Action}

Like other $\beta$-lactams, flomoxef acts by binding to penicillinbinding proteins (PBPs) (specific flomoxef affinities to PBP types are unknown), inhibiting cell wall synthesis and leading to bacterial cell death.

Unlike many other cephalosporins, flomoxef demonstrates high activity against staphylococci (including methicillin-resistant strains), most Enterobacterales and almost all anaerobes [142, 146, 147]. Important gaps in the spectrum of activity include enterococci, Pseudomonas, and Acinetobacter species [142, 143, 147].

\subsection{Resistance Mechanisms}

As a $\beta$-lactam, flomoxef resistance is predominantly via one of four mechanisms.

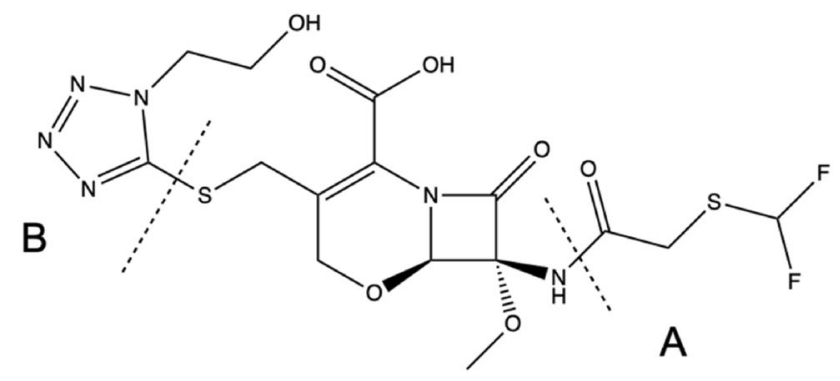

Flomoxef

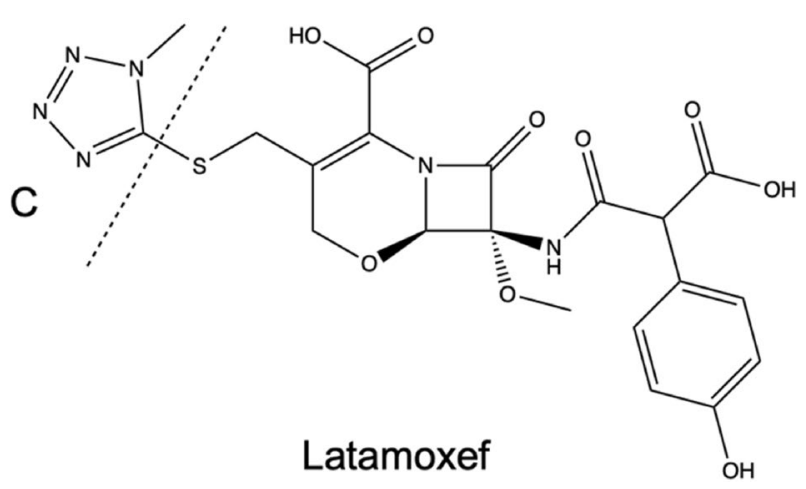

Fig. 3 Molecular structures of flomoxef and latamoxef. A 7- $\beta$-difluoromethyl-thioacetamido side chain, B methylthiadiazolethiol group, $\mathrm{C} \mathrm{N}$-methyltetrazolethiol group

\subsubsection{Hydrolysis by $\beta$-Lactamase Enzymes}

The predominant resistance mechanism for $\beta$-lactams is hydrolysis of the active $\beta$-lactam ring by bacterial $\beta$-lactamase enzymes. Oxacephems, including flomoxef, are stable to many $\beta$-lactamases, including ESBLs such as the CTX-M enzymes [143, 148-150], an attractive feature in the context of the rising incidence of ESBL-mediated AMR. However, flomoxef is susceptible to AmpC-like (i.e., Ambler class C) $\beta$-lactamases and carbapenems [150, 151]. This is potentially of concern because of the emergence of Klebsiella strains producing plasmid-mediated AmpC-like $\beta$-lactamases, which confer high flomoxef MICs [152].

Epidemiological studies have demonstrated that, because of flomoxef's overall stability to ESBLs, flomoxef susceptibility rates in bacteria are comparable to those of carbapenems, even in geographical regions where it is used widely (e.g., China) [148, 149, 153-157]. Retrospective studies have suggested that treatment of bloodstream infections caused by ESBL-producing bacteria is equally successful with either flomoxef or carbapenems [158-160], highlighting the potential use of flomoxef as a carbapenem-sparing agent. 


\subsubsection{Modifications of Penicillin-Binding Proteins (PBPs)}

Modification of target PBPs is another important resistance mechanism to $\beta$-lactams, e.g., PBP2a confers $\beta$-lactam resistance in methicillin-resistant $S$. aureus (MRSA). Flomoxef retains activity against MRSA [142] and appears to induce production of PBP2a to a lesser extent than other $\beta$-lactams [161]. Streptococcus pneumoniae also develops $\beta$-lactam resistance by a variety of PBP gene mutations, although many penicillin non-susceptible pneumococcal strains remain susceptible to flomoxef [149].

\subsubsection{Mutations in Porin Genes}

Mutations in porin genes can affect the antimicrobial penetration of $\beta$-lactams, although these have not been characterised in the context of flomoxef. However, some porin mutations (e.g., ompF) seem to produce small changes in the flomoxef MIC [150].

\subsubsection{Efflux}

As discussed in Sect. 3.2, many efflux mechanisms have been identified [37, 38], several of which affect $\beta$-lactams and may affect flomoxef, although no particular associations with flomoxef have been described.

\subsection{Clinical Pharmacokinetics}

Flomoxef is only formulated as an intravenous injection, with $C_{\max }$ occurring about $1 \mathrm{~h}$ post administration [136]. Protein binding is minimal at $<10 \%$ [162]. CSF penetration is limited, with a partition coefficient of $\sim 0.05$ in active meningitis in children [163].

Flomoxef is predominantly cleared by renal excretion, with $85 \%$ of the compound excreted unchanged within $6 \mathrm{~h}$ [136]. Involvement of active excretion via an organic anion transporter, possibly OAT1, is implied by competitive inhibition of renal clearance by co-administered probenecid [164, 165], although specific transporter associations have not been identified. However, there is some metabolic clearance, although the enzymatic mechanisms are poorly characterised. Flomoxef oxide is an active metabolite with approximately $25 \%$ of the activity of flomoxef [166]. However, clearance via this route only accounts for $\sim 0.1 \%$ of the total [167]. Metabolism to the inactive metabolite hydroxyethyl-tetrazolethinol accounts for approximately $10-15 \%$ of total clearance [167].

The adult $\beta$-phase half-life of flomoxef is approximately $50 \mathrm{~min}$ [136]. No single large pharmacokinetic study involving neonates has been conducted. However, many small neonatal studies involving flomoxef have estimated pharmacokinetic parameters for each dataset [168-177]. The parameters from these studies vary widely because of the high degree of inter-subject variability in age, weight, and gestation, with a median half-life of $2.21 \mathrm{~h}$ (range 0.68-6.6). However, all pharmacokinetic studies (adult and neonatal) were performed in a Japanese population, and validation of pharmacokinetic characteristics in non-Japanese populations is ideally required.

\subsection{Toxicity}

Other NMTT-containing oxacephems (e.g., latamoxef) exhibit coagulopathic side effects due to inhibition of vita$\min \mathrm{K}_{1} 2,3$-epoxide reductase. Flomoxef inhibits this enzyme at a lower affinity than other oxacephems, with coagulopathic toxicity not manifesting in clinical use [144, 145]. Additionally, many oxacephems induce a disulfiram-like reaction with co-administration of alcohol due to inhibition of aldehyde dehydrogenase [178, 179], but this does not appear to occur with flomoxef, because of its MTDT side chain substitution.

Flomoxef has only mild common side effects, with frequent gastrointestinal disturbance (possibly due to the effects on anaerobes in the gut), rash, eosinophilia, neutropenia, and drug fever $[145,180]$. Although most toxicity data have been determined from studies in adults, the limited toxicity data from neonatal pharmacokinetic studies [168-177] suggest a similar toxicity profile in neonates.

Rare side effects such as pneumonitis have been reported, although only in adults [181].

\subsection{Pharmacodynamics}

Previously, an assumption was made that the pharmacodynamics of flomoxef were similar to those of cephalosporins, with assumed pharmacodynamic targets of $40 \%$ (bacteriostatic) or $70 \%$ (bactericidal) time $>$ MIC [182-184]. However, a recent mouse thigh model determined targets of $40 \%$ and $25 \%$ time $>$ MIC for 1-log bacterial kill and stasis, respectively [185]. No pharmacodynamic target for prevention of emergence of resistance has been identified.

\subsection{Potential Utility in Neonatal Sepsis}

Flomoxef is an attractive option for neonatal sepsis in AMRprevalent settings. It has a broad spectrum of activity and intrinsic stability to non-AmpC-type ESBLs, with low resistance rates epidemiologically. Significant neonatal pharmacokinetic data are also available (albeit only in Japanese populations), and it has a safe toxicity profile. The pharmacodynamics of bactericidal killing have also recently been described, although pharmacodynamic characterisation for emergence of resistance is still lacking. The main barrier to 
the use of flomoxef is the lack of regulatory approval outside of East Asia.

\section{Cefepime}

Cefepime is a $\beta$-lactam and fourth-generation cephalosporin. Cephalosporins are $\beta$-lactam antibiotics derived from the prototypical molecule cephalosporin $\mathrm{C}$, isolated from a Cephalosporium (now referred to as Acremonium) species of fungi in the 1950s [186]. Subsequently, dozens of derivatives of this molecule have been created [138]. These are broadly categorised into generations, with successive generations generally having broader spectra of activity and greater activity in the presence of resistance mechanisms than earlier generations.

Cefepime is an aminothiazolyl methoxyimino cephalosporin that is structurally similar to third-generation cephalosporins such as ceftriaxone and cefotaxime (Fig. 4). It has an $N$-methyl-pyrrolidine moiety at the $3^{\prime}$ position that confers zwitterionic properties [187]. This feature allows the drug to penetrate the Gram-negative bacterial outer membrane more rapidly than other $\beta$-lactams [188, 189].

\subsection{Mechanism of Action}

Like other $\beta$-lactams, cefepime inhibits cell wall synthesis by binding to PBPs (with particular affinities demonstrated for PBPs 2 and 3 in Escherichia coli [190]), inhibiting the peptidoglycan synthesis pathway and leading to cell lysis and death. Cefepime has a broad spectrum of activity affecting both Gram-positive and Gram-negative bacteria, including pseudomonads [191]. However, like other cephalosporins, it lacks activity against anaerobic bacteria [192].

\subsection{Resistance Mechanisms}

Like other $\beta$-lactams, resistance to cefepime occurs by one of four main mechanisms.

\subsubsection{Hydrolysis by $\beta$-Lactamase Enzymes}

As discussed in Sect. 5.2, the most common resistance mechanism to $\beta$-lactams is hydrolysis by $\beta$-lactamases. Compared with other $\beta$-lactams, cefepime is significantly more stable to $\beta$-lactamases [193]. Compared with other cephalosporins, such as cefotaxime and ceftazidime, AmpC-like ESBLs have a lower affinity and hydrolysis rate to cefepime [194, 195], albeit with an associated inoculum effect [196, 197]. However, cefepime has affinity and lability to nonAmpC ESBLs [193, 195, 198]. Although cefepime MICs for ESBL-producing bacteria may fall below the European Committee on Antimicrobial Susceptibility Testing/Clinical Laboratory Standards Institute (CLSI) breakpoints for this drug [199], the use of cefepime against these bacteria has been associated with clinical failure [199, 200].

\subsubsection{Modification of Target PBPs}

Modification of the target PBP is a common resistance mechanism in Gram-positive bacteria. As with most other $\beta$-lactams, production of PBP $2 \mathrm{a}$ in MRSA confers resistance to cefepime [201].

\subsubsection{Mutations in Porin Genes}

Many $\beta$-lactams, including cefepime, require porins to enter the bacterial cell [202]. E. coli and Klebsiella strains with loss or downregulation of genes encoding the porins OmpA, OmpC, and/or OmpF exhibit a two- to fourfold increase in the cefepime MIC [203]. Additionally, loss of the porin
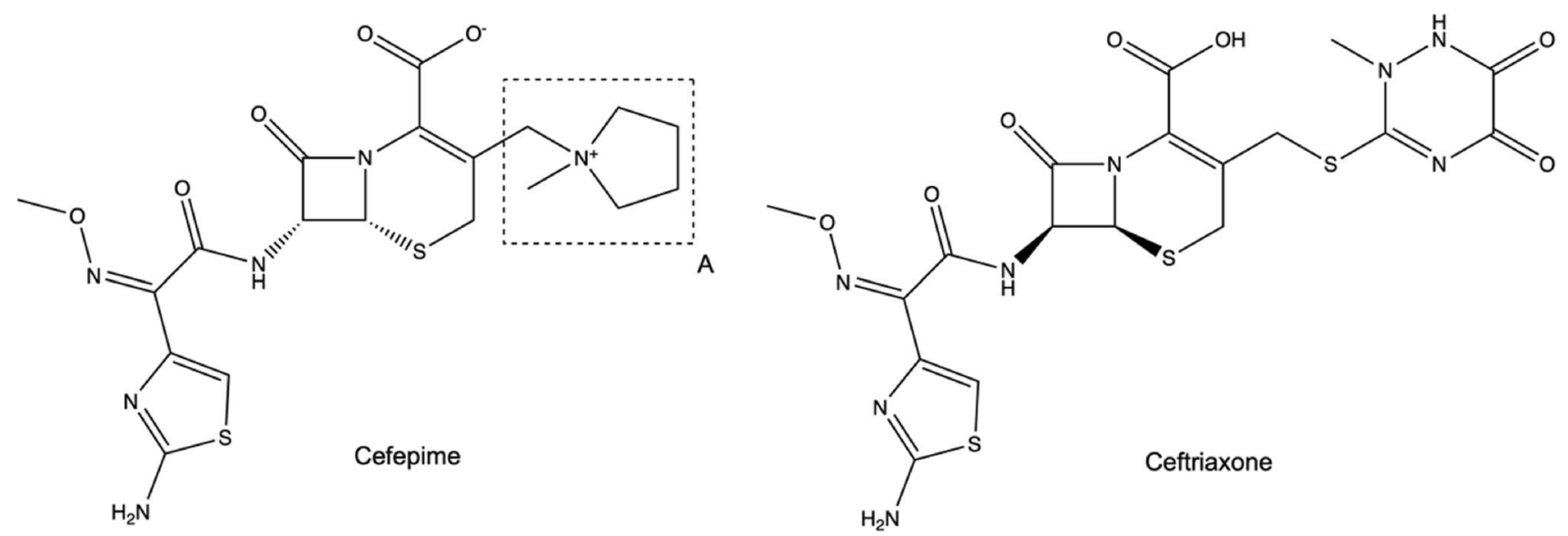

Fig. 4 Molecular structures of cefepime and ceftriaxone. A $N$-methyl-pyrrolidine moiety 
Omp36 in Klebsiella aerogenes (homologous to OmpC in E. coli and OmpK36 in Klebsiella pneumoniae) has been associated with a fourfold increase in cefepime MIC [204].

\subsubsection{Efflux}

As discussed in Sect. 3.2, many bacteria efflux pumps have been characterised [37, 38], several of which affect $\beta$-lactams. No comprehensive cataloguing of the efflux pumps that affect cefepime has been performed. However, $P$. aeruginosa strains overexpressing Mex-AB-OprM, Mex$\mathrm{XY}-\mathrm{OprM}$, and/or Mex-CA-OprJ have been associated with an increased cefepime MIC [205, 206].

\subsection{Clinical Pharmacokinetics}

The half-life of cefepime in adults is approximately $2 \mathrm{~h}$, with a $C_{\max }$ increasing linearly with the administered dose [207, 208]. There is some protein binding, with binding rates of $16.2-19 \%$ to human serum proteins [191, 209]. Two cefepime neonatal pharmacokinetic trials have been performed with doses of 30 and $50 \mathrm{mg} / \mathrm{kg}$ [210, 211]. The calculated half-lives were $4.9 \pm 2.1$ and $4.32 \pm 1.8 \mathrm{~h}$ with $C_{\max }$ values of $89 \pm 27$ and $120.9 \pm 38.5 \mathrm{mg} / \mathrm{L}$, respectively.

Cefepime distributes readily into the soft tissue, with rapid penetration into inflammatory fluid, with close matching to plasma concentrations $[212,213]$. Mean adult $V_{\mathrm{d}}$ is $\sim 18-21 \mathrm{~L}[212,214]$; neonatal $V_{\mathrm{d}}$ is $\sim 0.4 \mathrm{~L} / \mathrm{kg}$, although this increases with decreasing gestation below 30 weeks [211].

Adult CSF penetrance is variable, with partition coefficients of 0.05-0.34 [215]. A small neonatal study $(n=9)$ suggested similarly variable CSF penetrance, with a median partition coefficient of 0.077 (range 0.030-0.876) [216].

Cefepime is primarily renally excreted, with $\sim 80 \%$ of administered drug recovered unchanged in the urine [208]. Approximately $10-12 \%$ of administered cefepime is metabolised. Approximately $7 \%$ is metabolised first to $N$-methylpyrrolidine and then rapidly oxidised to $N$-methylpyrrolidine- $\mathrm{N}$-oxide. Another 3\% is metabolised to the 7 -epimer of cefepime [217]. The overall rate of clearance in neonates is variable, ranging from 0.5 to $2.5 \mathrm{~mL} / \mathrm{min} / \mathrm{kg}$ (gestational age only marginally accounts for this variability) [211].

No specific transporters have been associated with cefepime transport; however, cefepime inhibits (but is not transported by) OCTN2 [218]. Unlike some other $\beta$-lactams, cefepime has no affinity to the intestinal transporter PEPT1, which likely explains its poor oral bioavailability [219].

\subsection{Toxicity}

Cefepime is a largely safe drug with common side effects being usually mild and similar to those affecting other $\beta$-lactams, e.g., gastrointestinal disturbance, rash, etc. [221, 222].

Cefepime is associated with rare neurotoxic side effects, which are heterogenous (presentations include encephalopathy, myoclonus, seizures, and coma) and usually start several days into treatment [223]. The neurotoxicity appears to be concentration dependent [223, 224] and associated with renal dysfunction and critical illness [223] and is thought to be due to concentration-dependent inhibition of $\mathrm{GABA}_{\mathrm{A}}$-mediated neurotransmission [225]. This toxicity is mainly associated with increasing age and renal dysfunction [223], the latter of potential concern in neonates.

An initial meta-analysis of cefepime outcome data suggested a possible increased mortality associated with cefepime use compared with other $\beta$-lactams (including in paediatric populations) [226, 227]. However, two further meta-analyses (with combined adult and paediatric data, and with paediatric data alone, respectively) showed no statistically significant increase in mortality associated with cefepime use [228, 229]. Further retrospective studies of paediatric and neonatal patients receiving cefepime failed to show any statistically significant excess mortality [230-232].

\subsection{Pharmacodynamics}

Cefepime is presumed to have the same pharmacodynamic index as other cephalosporins, with a pharmacodynamic target of 60-70\% time $>$ MIC producing maximal effect [220]. A pharmacokinetic model and Monte Carlo simulation suggested that the widely used dose of $30 \mathrm{mg} / \mathrm{kg}$ administered 12 hourly would achieve a target $50 \%$ time $>$ MIC for the CLSI-recommended breakpoint concentration for $99 \%$ of neonatal patients [211].

\subsection{Potential Utility in Neonatal Sepsis}

Cefepime has a broad spectrum of activity and, although not specifically licensed for neonatal use, experience with it in neonatal settings is extensive. Its reduced affinity for ESBLs render it potentially useful in AMR-prevalent settings, and it has a safe toxicity profile in neonates.

However, although it may be reasonable to assume characteristics similar to those of other cephalosporins, specific pharmacodynamic characterisation is lacking and, despite its reduced affinity to ESBLs, it remains labile to non-AmpC ESBLs in in vitro settings $[195,198]$ and has a poorer than expected clinical record for treatment of ESBL-producing bacteria [199, 200]. These characteristics may limit its utility in neonatal sepsis in ESBL-prevalent areas. 


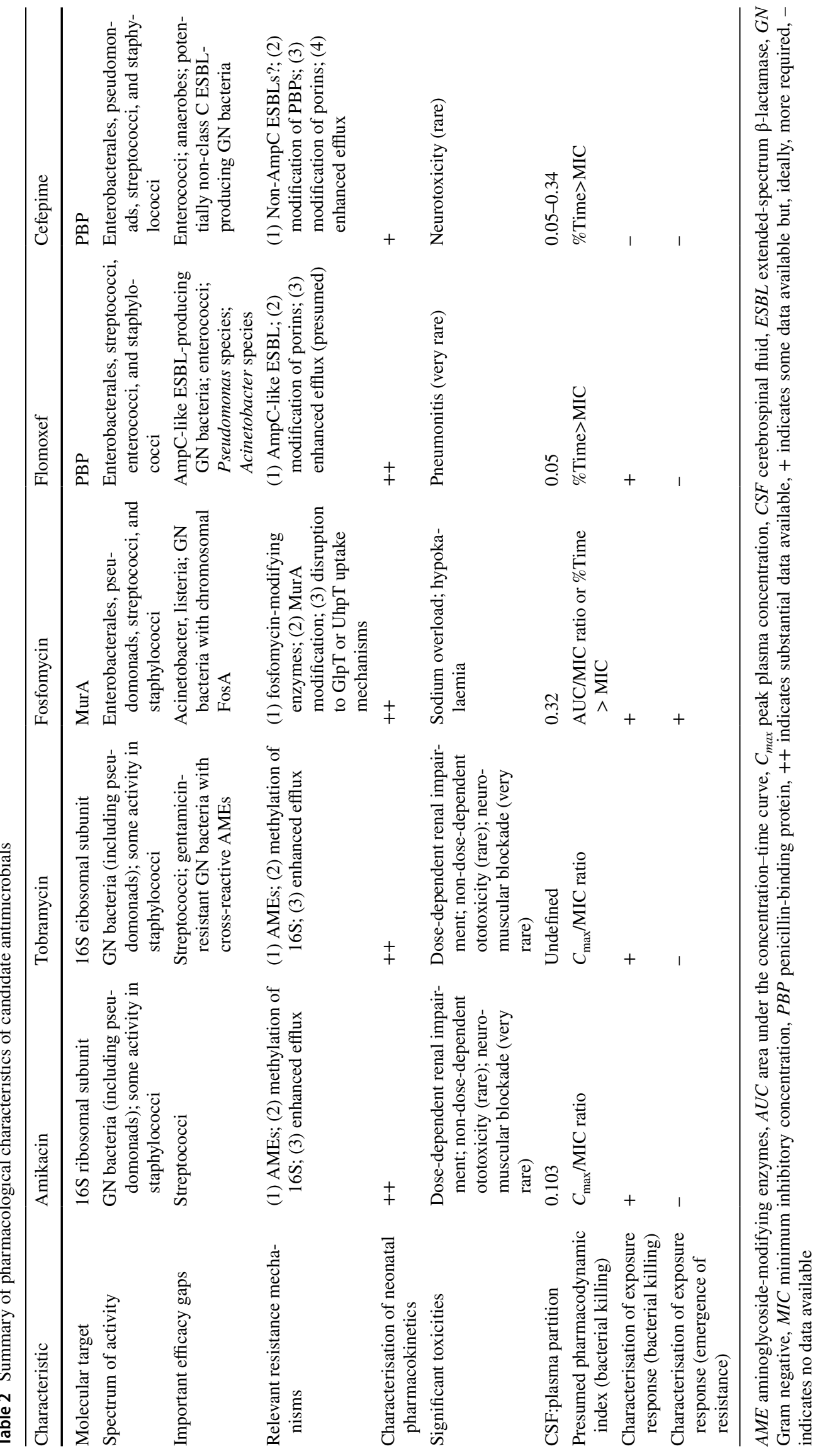




\section{Summary}

These five antimicrobials all have characteristics that make them potential candidates for an empiric antimicrobial regimen for neonatal sepsis (Table 2). All demonstrate spectra of activity against bacteria that cause neonatal sepsis with prevalent mechanisms of resistance that are problematic for the current WHO-recommended regimen: amikacin and tobramycin offer activity against gentamicinresistant Gram-negative bacteria; flomoxef and cefepime have enhanced stability to ESBLs compared with other $\beta$-lactams; and fosfomycin still retains widespread activity against bacteria with resistance mechanisms to other classes. However, although they fulfil the selection criteria, both tobramycin and cefepime have a narrower spectrum of activity than the alternatives because of their lability to cross-reactive AMEs and non-AmpC ESBLs, respectively. This makes these agents less attractive than the other three agents.

All drugs are also off patent and have potential to be produced at an affordable rate for LMICs. Additionally, all drugs have favourable toxicity profiles, with toxicities being limited and predictable where they occur. All also have a licence for, or significant experience in the treatment of, neonatal infections (although licensing for fosfomycin and flomoxef remains geographically limited, which would need addressing via, for example, expediated local regulatory approval, should they be selected in an eventual empiric regimen).

Nevertheless, there are some key gaps in the pharmacological data available for neonates (Table 2). Although the clinical pharmacokinetics of all these drugs are well described for adults, the data are more limited in neonates. Neonatal pharmacokinetic data for fosfomycin are largely underpinned by a single large pharmacokinetic study [119]; those for cefepime rely on two relevant neonatal pharmacokinetic studies [210, 211]; and flomoxef pharmacokinetic data are absent in non-Japanese populations. Furthermore, knowledge of CSF penetration is limited in some agents. Neonatal CSF:plasma coefficients have not been determined for tobramycin [233], and the flomoxef coefficient is dependent on a single study [163]. The CSF penetration data available for the five agents compare well to those of the WHO regimen ( $\sim 0$ for gentamicin $[49,50]$; $0.05-0.1$ for amoxicillin [234]).

The other key knowledge gap is the pharmacodynamic characterisation of these drugs. Flomoxef has recently been characterised in terms of bactericidal killing, but the characterisation of other agents is more limited. For cefepime and the aminoglycosides, the exposure-response relationships and pharmacodynamic targets are presumed to be similar to those of the other molecules within the same class, but these have not been determined independently. For fosfomycin, published evidence has definitively established neither the pharmacodynamic index nor the target. Furthermore, the exposure-response relationship and pharmacodynamic targets for prevention of emergence of resistance have been poorly characterised in all agents.

In addition to consideration of each agent's pharmacological characteristics, an eventual regimen selection is dependent on the epidemiology of resistance and manufacturing costs. As discussed in Sect. 1, high-quality observational studies of neonatal sepsis across multiple geographical locations are rare. Amongst these studies, reported resistance rates for these particular agents are rarer still. The single high-quality neonatal sepsis study reporting rates of resistance to these antibiotics indicated $63 \%, 55 \%, 25 \%$, and $18 \%$ of Gram-negative bacteria (including non-Enterobacterales, e.g., Acinetobacter species) were resistant for tobramycin, cefepime, amikacin, and fosfomycin, respectively [9]. There are no data indicating the level of resistance to flomoxef in bacteria causing neonatal sepsis. However, as discussed in Sect. 5.2, flomoxef resistance is consistently seen in $\leq 10 \%$ isolates of Enterobacterales causing non-neonatal infections in geographic regions where flomoxef is currently used [149, 153, 155-157]. A further multi-centre neonatal sepsis observational cohort study, NeoOBS, is expected to report soon with AMR data for flomoxef, fosfomycin, and amikacin [235].

The current cost of each agent per vial is detailed in Table 3. Although more expensive than current WHO regimen antibiotics, the material costs of the five agents are potentially affordable in LMIC settings. Reformulation of vial size quantities relevant to paediatric or neonatal requirements could lower the material costs. Furthermore, many of the agents are only produced by a small number of generic manufacturers (e.g., intravenous fosfomycin); expansion of these could lower the costs further [236].

Table 3 Comparative costs of the World Health Organization regimen antibiotics and the five reviewed antibiotics and typical neonatal regimen

\begin{tabular}{lll}
\hline Antibiotic & Material cost (\$US) & Typical neonatal regimen \\
\hline Gentamicin & $1.91 / 80 \mathrm{mg} \mathrm{[237]}$ & $5 \mathrm{mg} / \mathrm{kg} \mathrm{q} 24 \mathrm{~h}$ \\
Amoxicillin & $0.45 / 250 \mathrm{mg} \mathrm{[237]}$ & $30 \mathrm{mg} / \mathrm{kg} \mathrm{q} 8 \mathrm{~h}$ \\
Amikacin & $2.86 / 100 \mathrm{mg} \mathrm{[237]}$ & $15 \mathrm{mg} / \mathrm{kg} \mathrm{q} 24 \mathrm{~h}$ \\
Tobramycin & $7.43 / 80 \mathrm{mg} \mathrm{[237]}$ & $5 \mathrm{mg} / \mathrm{kg} \mathrm{q} 24 \mathrm{~h}$ \\
Fosfomycin & $20.75 / 2 \mathrm{~g} \mathrm{[237]}$ & $100 \mathrm{mg} / \mathrm{kg} \mathrm{q} 12 \mathrm{~h}$ \\
Flomoxef & $2.97 / 1 \mathrm{~g} \mathrm{[238]}$ & $20 \mathrm{mg} / \mathrm{kg} \mathrm{q} 8-12 \mathrm{~h}$ \\
Cefepime & $7.61 / 1 \mathrm{~g} \mathrm{[237]}$ & $30 \mathrm{mg} / \mathrm{kg} \mathrm{q} 8-12 \mathrm{~h}$ \\
\hline
\end{tabular}

Costs converted to \$US using conversion rates on 15 July 2021 $q x h$ every $\mathrm{x} h, q 8-12 h$ every $8-12 \mathrm{~h}$ 
An alternate first-line regimen for the empiric treatment of neonatal sepsis will likely have to be a combination of two of these agents to provide the necessary spectrum coverage to treat target pathogens and resistance motifs and protect against emergence of resistance to both agents. A positive pharmacodynamic interaction (e.g., synergy) is also desirable. Selection of an appropriate regimen from these agents will therefore be dependent on the AMR epidemiology in LMIC settings, characterisation of the pharmacodynamics of these agents (alone and in combination), and testing of candidate regimens in a clinical trial.

\section{Declarations}

Funding No specific funding was received for this work. CD received general funding from the UK Medical Research Council (MR/ N025989/1). RMAC, SE, FF and LP completed this work as part of their routine roles at the Global Antibiotic Research and Development Partnership (GARDP). MS completed this work as part of his routine role at St George's University of London. SD and WH completed this work as part of their routine roles at the University of Liverpool.

Conflict of interest Not applicable.

Ethics approval Not applicable.

Consent to participate Not applicable.

Consent for publication Not applicable.

Availability of data and material Not applicable.

Code availability Not applicable.

Author contributions $\mathrm{CD}$ was the primary author of the manuscript. $\mathrm{CD}, \mathrm{RdC}, \mathrm{SE}, \mathrm{FF}, \mathrm{MS}, \mathrm{LP}, \mathrm{SD}$, and WH all contributed to the conception of the review and contents and critically reviewed and revised the manuscript.

Open Access This article is licensed under a Creative Commons Attribution-NonCommercial 4.0 International License, which permits any non-commercial use, sharing, adaptation, distribution and reproduction in any medium or format, as long as you give appropriate credit to the original author(s) and the source, provide a link to the Creative Commons licence, and indicate if changes were made. The images or other third party material in this article are included in the article's Creative Commons licence, unless indicated otherwise in a credit line to the material. If material is not included in the article's Creative Commons licence and your intended use is not permitted by statutory regulation or exceeds the permitted use, you will need to obtain permission directly from the copyright holder. To view a copy of this licence, visit http://creativecommons.org/licenses/by-nc/4.0/.

\section{References}

1. Lawn JE, Blencowe H, Oza S, You D, Lee ACC, Waiswa P, et al. Every newborn: progress, priorities, and potential beyond survival. Lancet. 2014;384:189-205.
2. Oza S, Lawn JE, Hogan DR, Mathers C, Cousens SN. Neonatal cause-of-death estimates for the early and late neonatal periods for 194 countries: 2000-2013. Bull World Health Organ. 2015;93:19-28.

3. Fleischmann-Struzek C, Goldfarb DM, Schlattmann P, Schlapbach LJ, Reinhart K, Kissoon N. The global burden of paediatric and neonatal sepsis: a systematic review. Lancet Respir Med. 2018;6:223-30. https://doi.org/10.1016/S2213-2600(18) 30063-8.

4. Seale AC, Blencowe H, Manu AA, Nair H, Bahl R, Qazi SA, et al. Estimates of possible severe bacterial infection in neonates in sub-Saharan Africa, south Asia, and Latin America for 2012: a systematic review and meta-analysis. Lancet Infect Dis. 2014;14:731-41. https://doi.org/10.1016/S1473-3099(14) 70804-7.

5. Fuchs A, Bielicki J, Mathur S, Sharland M, Van JN, Anker D. Antibiotic use for sepsis in neonates and children: 2016 evidence update. WHO Reviews. 2016. http://www.who.int/selection medicines/committees/expert/21/applications/s6_paed_antib iotics_appendix4_sepsis.pdf

6. World Health Organization. Pocket book of hospital care for children. 2nd ed. Geneva: World Health Organisation; 2013.

7. Shane AL, Sánchez PJ, Stoll BJ. Neonatal sepsis. Lancet. 2017;390:1770-80.

8. O'Neill J. Antimicrobial resistance: tackling a crisis for the health and wealth of nations. Rev Antimicrob Resist 2014. https://amrreview.org/Publications.html

9. Sands K, Carvalho MJ, Portal E, Thomson K, Dyer C, Akpulu C, et al. Characterization of antimicrobial-resistant Gram-negative bacteria that cause neonatal sepsis in seven low- and middleincome countries. Nat Microbiol Nat Microbiol. 2021;6:512-23.

10. Investigators of the DeNIS collaboration. Characterisation and antimicrobial resistance of sepsis pathogens in neonates born in tertiary care centres in Delhi, India: a cohort study. Lancet Glob Health. 2016;4:752-60. https://doi.org/10.1016/S2214-109X(16) 30148-6

11. Labi AK, Obeng-Nkrumah N, Bjerrum S, Enweronu-Laryea C, Newman MJ. Neonatal bloodstream infections in a Ghanaian Tertiary Hospital: are the current antibiotic recommendations adequate? BMC Infect Dis. 2016. https://doi.org/10.1186/ s12879-016-1913-4.

12. Bandyopadhyay T, Kumar A, Saili A, Randhawa VS. Distribution, antimicrobial resistance and predictors of mortality in neonatal sepsis. J Neonatal Perinatal Med. 2018;11:145-53.

13. Jajoo M, Manchanda V, Chaurasia S, Jeeva Sankar M, Gautam $\mathrm{H}$, Agarwal R, et al. Alarming rates of antimicrobial resistance and fungal sepsis in outborn neonates in North India. PLoS ONE. 2018;13:1-16.

14. Yadav NS, Sharma S, Chaudhary DK, Panthi P, Pokhrel P, Shrestha A, et al. Bacteriological profile of neonatal sepsis and antibiotic susceptibility pattern of isolates admitted at Kanti Children's Hospital Kathmandu Nepal. BMC Res Notes BioMed Central. 2018;11:1-6. https://doi.org/10.1186/s13104-018-3394-6.

15. Pokhrel B, Koirala T, Shah G, Joshi S, Baral P. Bacteriological profile and antibiotic susceptibility of neonatal sepsis in neonatal intensive care unit of a tertiary hospital in Nepal. BMC Pediatr BMC Pediatrics. 2018;18:1-8.

16. Chaurasia S, Sivanandan S, Agarwal R, Ellis S, Sharland M, Sankar MJ. Neonatal sepsis in South Asia: huge burden and spiralling antimicrobial resistance. BMJ. 2019;364:K5314.

17. Noel GJ, Nambiar S, Bradley J. Advancing pediatric antibacterial drug development: a critical need to reinvent our approach. J Pediatric Infect Dis Soc. 2019;8:60-2.

18. Folgori L, Ellis SJ, Bielicki JA, Heath PT, Sharland M, Balasegaram M. Tackling antimicrobial resistance in neonatal sepsis. 
Lancet Glob Health. 2017;5:1066-8. https://doi.org/10.1016/ S2214-109X(17)30362-5.

19. Grayson ML, Cosgrove SE, Crowe S, Hope WW, McCarthy JS, Mills J, et al editors. Kucers' the use of antibiotics. 7th ed. Boca Raton: CRC Press; 2017.

20. Krause KM, Serio AW, Kane TR, Connolly LE. Aminoglycosides: an overview. Cold Spring Harb Perspect Med. 2016;6:a027029

21. Ramirez MS, Tolmasky ME. Aminoglycoside modifying enzymes. Drug Resist Update. 2010;13:151-71. https://doi.org/ 10.1016/j.drup.2010.08.003.

22. Kawaguchi H, Naito T, Nakagawa S, Fujisawa KI. BB-K 8, a new semisynthetic aminoglycoside antibiotic. J Antibiot (Tokyo). 1972;25:695-708.

23. Neu HC. Tobramycin: an overview. J Infect Dis. 1976;134(Suppl):S3-19.

24. Waterworth PM. The in-vitro activity of tobramycin compared with that of other aminoglycosides. J Clin Pathol. 1972;25:979-83.

25. Siegenthaler WE, Bonetti A, Luthy R. Aminoglycoside antibiotics in infectious diseases. An overview. Am J Med. 1986;80:2-14.

26. Vanhoof R, Sonck P, Hannecart-Pokorni E. The role of lipopolysaccharide anionic binding sites in aminoglycoside uptake in Stenotrophomonas (Xanthomonas) maltophilia. J Antimicrob Chemother. 1995;35:167-71.

27. Bryan LE, Van Den Elzen HM. Effects of membrane-energy mutations and cations on streptomycin and gentamicin accumulation by bacteria: a model for entry of streptomycin and gentamicin in susceptible and resistant bacteria. Antimicrob Agents Chemother. 1977;12:163-77.

28. Shaw KJ, Rather PN, Hare RS, Miller GH. Molecular genetics of aminoglycoside resistance genes and familial relationships of the aminoglycoside-modifying enzymes. Microbiol Rev. 1993;57:138-63.

29. Doi Y, Wachino J, Arakawa Y. Aminoglycoside resistance: the emergence of acquired 16S ribosomal RNA methyltransferases. Infect Dis Clin N Am. 2016;30:523-37.

30. Saravolatz LD, Stein GE. Plazomicin: a new aminoglycoside. Clin Infect Dis. 2020;70:704-9.

31. Berçot B, Poirel L, Nordmann P. Plasmid-mediated 16S rRNA methylases among extended-spectrum $\beta$-lactamase-producing Enterobacteriaceae isolates. Antimicrob Agents Chemother. 2008;52:4526-7.

32. Suzuki Y, Katsukawa C, Tamaru A, Abe C, Makino M, Mizuguchi $\mathrm{Y}$, et al. Detection of kanamycin-resistant Mycobacterium tuberculosis by identifying mutations in the 16S rRNA gene. J Clin Microbiol. 1998;36:1220-5.

33. Cooksey RC, Morlock GP, Mcqueen A, Glickman SE, Crawford JT. Characterization of streptomycin resistance mechanisms among Mycobacterium tuberculosis isolates from patients in New York City. Antimicrob Agents Chemother. 1996;40:1186-8.

34. Prammananan T, Sander P, Brown BA, Frischkorn K, Onyi GO, Zhang Y, et al. A single $16 \mathrm{~S}$ ribosomal RNA substitution is responsible for resistance to amikacin and other 2-deoxystreptamine aminoglycosides in Mycobacterium abscessus and Mycobacterium chelonae. J Infect Dis. 1998;177:1573-81.

35. Garneau-tsodikova S, Labby KJ. Mechanisms of resistance to aminoglycoside antibiotics: overview and perspectives. Medchemcomm. 2016;7:11-27.

36. Yuan W, Hu Q, Cheng H, Shang W, Liu N, Hua Z, et al. Cell wall thickening is associated with adaptive resistance to amikacin in methicillin-resistant Staphylococcus aureus clinical isolates. J Antimicrob Chemother. 2013;68:1089-96.

37. Li X-Z, Nikaido H. Efflux-mediated drug resistance in bacteria: an update. Drugs. 2009;69:1555-623.
38. Blair JMA, Richmond GE, Piddock LJV. Multidrug efflux pumps in Gram-negative bacteria and their role in antibiotic resistance. Fut Microbiol. 2014;9:1165-77.

39. Islam S, Jalal S, Wretlind B. Expression of the MexXY efflux pump in amikacin-resistant isolates of Pseudomonas aeruginosa. Clin Microbiol Infect. 2004;10:877-83.

40. Auwera P. Pharmacokinetic evaluation of single daily dose amikacin. J Antimicrob Chemother. 1991;27(Suppl C):63-71.

41. Naber KG, Westenfelder SR, Madsen PO. Pharmacokinetics of the aminoglycoside antibiotic tobramycin in humans. Antimicrob Agents Chemother. 1973;3:469-73.

42. Howard JB, McCracken GH. Pharmacological evaluation of amikacin in neonates. Antimicrob Agents Chemother. 1975;8:86-90.

43. Yoshioka H, Takimoto M, Fujita K, Maruyama S. Pharmacokinetics of tobramycin in the newborn. Infection. 1979;7:180-2.

44. Howard JB, McCracken GH, Trujillo H, Mohs HE. Amikacin in newborn infants: comparative pharmacology with kanamycin and clinical efficacy in 45 neonates with bacterial diseases. Antimicrob Agents Chemother. 1976;10:205-10.

45. Arbeter AM, Saccar CL, Saccar L, Eisner S, Sarni E, Yaffe SJ. Tobramycin sulfate elimination in premature infants. J Pediatr. 1983;103:131-5.

46. Briedis D, Robson H. Cerebrospinal fluid penetration of antimicrobials. Antimicrob Agents Chemother. 1978;13:1042-3.

47. Allegaert K, Scheers I, Adams E, Brajanoski G, Cossey V, Anderson BJ. Cerebrospinal fluid compartmental pharmacokinetics of amikacin in neonates. Antimicrob Agents Chemother. 2008;52:1934-9.

48. Tessin I, Trollfors B, Thiringer K, Thörn Z, Larsson P. Concentrations of ceftazidime, tobramycin and ampicillin in the cerebrospinal fluid of newborn infants. Eur J Pediatr. 1989;148:679-81.

49. Chang MJ, Escobedo M, Anderson DC, Hillman L, Feigin RD. Kanamycin and gentamicin treatment of neonatal sepsis and meningitis. Pediatrics. 1975;56:695-9.

50. Pickering LK, Ericsson CD, Ruiz Palacios G, Blevins J, Miner ME. Intraventricular and parenteral gentamicin therapy for ventriculitis in children. Am J Dis Child. 1978;132:480-3.

51. Clarke JT, Libke RD, Regamey C, Kirby WMM. Comparative pharmacokinetics of amikacin and kanamycin. Clin Pharmacol Ther. 1974;15:610-6.

52. Gordon RC, Regamey C, Kirby WM. Serum protein binding of the aminoglycoside antibiotics. Antimicrob Agents Chemother. 1972;2:214-6.

53. Regamey C, Gordon RC, Kirby WMM. Comparative pharmacokinetics of tobramycin and gentamicin. Clin Pharmacol Ther. 1973;14:396-403.

54. Schentag JJ, Lasezkay G, Cumbo TJ, Plaut ME, Jusko WJ. Accumulation pharmacokinetics of tobramycin. Antimicrob Agents Chemother. 1978;13:649-56.

55. Padovani EM, Pistolesi C, Fanos V, Messori A, Martini N. Pharmacokinetics of amikacin in neonates. Dev Pharmacol Ther. 1993;20:167-73.

56. Nagai J, Takano M. Entry of aminoglycosides into renal tubular epithelial cells via endocytosis-dependent and endocytosis-independent pathways. Biochem Pharmacol. 2014;90:331-7. https:// doi.org/10.1016/j.bcp.2014.05.018.

57. Nagai J, Tanaka H, Nakanishi N, Murakami T, Takano M. Role of megalin in renal handling of aminoglycosides. Am J Physiol Physiol. 2001;281:F337-44.

58. Tauris J, Christensen EI, Nykjær A, Jacobsen C, Petersen CM, Ovesen T. Cubilin and megalin co-localize in the neonatal inner ear. Audiol Neurotol. 2009;14:267-78.

59. Myrdal SE, Steyger PS. TRPV1 regulators mediate gentamicin penetration of cultured kidney cells. Hear Res. 2005;204:170-82. 
60. Karasawa T, Wang Q, Fu Y, Cohen DM, Steyger PS. TRPV4 enhances the cellular uptake of aminoglycoside antibiotics. J Cell Sci. 2008;121:2871-9.

61. Mingeot-Leclercq M-P, Tulkens PM. Aminoglycosides: nephrotoxicity. Antimicrob Agents Chemother. 1999;43:1003-12.

62. Barza M, Ioannidis JP, Cappelleri JC, Lau J. Single or multiple daily doses of aminoglycosides: a meta-analysis. BMJ. 1996;312:338-45.

63. Kent A, Turner MA, Sharland M, Heath PT. Aminoglycoside toxicity in neonates: something to worry about? Expert Rev Anti Infect Ther. 2014;12:319-31.

64. Rao SC, Srinivasjois R, Hagan R, Ahmed M. One dose per day compared to multiple doses per day of gentamicin for treatment of suspected or proven sepsis in neonates. Cochrane Database Syst Rev. 2016;12:CD005091.

65. Hughes KM, Johnson PN, Anderson MP. Comparison of amikacin pharmacokinetics in neonates following implementation of a new dosage protocol. J Pediatr Pharmacol Ther. 2017;22:33-40.

66. Langhendries JP, Battisti O, Bertrand JM, François A, Darimont $\mathrm{J}$, Ibrahim S, et al. Once-a-day administration of amikacin in neonates: assessment of nephrotoxicity and ototoxicity. Dev Pharmacol Ther. 1993;20:220-30.

67. Kotze A, Bartel PR, Sommers DK. Once versus twice daily amikacin in neonates: prospective study on toxicity. J Paediatr Child Health. 1999;35:283-6.

68. Guthrie OW. Aminoglycoside induced ototoxicity. Toxicology. 2008;249:91-6.

69. Jing W, Zongjie H, Denggang F, Na H, Bin Z, Aifen Z, et al. Mitochondrial mutations associated with aminoglycoside ototoxicity and hearing loss susceptibility identified by meta-analysis. J Med Genet. 2015;52:95-103.

70. De Hoog M, Van Zanten GA, Hoeve LJ, Blom AM, Van Den Anker JN. A pilot case control follow-up study on hearing in children treated with tobramycin in the newborn period. Int $\mathrm{J}$ Pediatr Otorhinolaryngol. 2002;65:225-32.

71. Hashimoto Y, Shima T, Matsukawa S, Satou M. A possible hazard of prolonged neuromuscular blockade by amikacin. Anesthesiology. 1978;49:219-20.

72. Singh YN, Marshall IG, Harvey AL. Some effects of the aminoglycoside antibiotic amikacin on neuromuscular and autonomic transmission. Br J Anaesth. 1978;50:109-17.

73. Gilliard V, Delvaux B, Russell K, Dubois PE. Long-lasting potentiation of a single-dose of rocuronium by amikacin: case report. Acta Anaesthesiol Belg. 2006;57:157-9.

74. Gerber AU, Craig WA, Brugger HP, Feller C, Vastola AP, Brandel J. Impact of dosing intervals on activity of gentamicin and ticarcillin against $P$ seudomonas aeruginosa in granulocytopenic mice. J Infect Dis. 1983;147:910-7.

75. Kapusnik JE, Hackbarth CJ, Chambers HF, Carpenter T, Sande MA. Single, large, daily dosing versus intermittent dosing of tobramycin for treating experimental Pseudomonas pneumonia. J Infect Dis. 1988;158:7-12.

76. Gerber AU, Feller-Segessenmann C. In-vivo assessment of invitro killing patterns of Pseudomonas aeruginosa. J Antimicrob Chemother. 1985;15:201-6.

77. Vogelman B, Gudmundsson S, Turnidge J, Leggett J, Craig WA, Vogelman B. In vivo postantibiotic effect in a thigh infection in neutropenic mice. J Infect Dis. 1988;157:287-98.

78. Gerber AU, Wiprächtiger P, Stettler-Spichiger U, Lebek G. Constant infusions vs intermittent doses of gentamicin against Pseudomonas aeruginosa in vitro. J Infect Dis. 1982;145:554-60.

79. Vogelman B, Gudmundsson S, Leggett J, Turnidge J, Ebert S, Craig WA. Correlation of antimicrobial pharmacokinetic parameters with therapeutic efficacy in an animal model. J Infect Dis. 1988;158:831-47.
80. Moore RD, Lietman PS, Smith CR. Clinical response to aminoglycoside therapy: importance of the ratio of peak concentration to minimal inhibitory concentration. J Infect Dis. 1987;155:93-9.

81. Moore RD, Smith CR, Lietman PS. Association of aminoglycoside plasma levels with therapeutic outcome in gram-negative pneumonia. Am J Med. 1984;77:657-62.

82. Moore RD, Smith CR, Lietman PS. The association of aminoglycoside plasma levels with mortality in patients with gramnegative bacteremia. J Infect Dis. 1984;149:443-8.

83. Klastersky J, Daneau D, Swings G, Weerts D. Antibacterial activity in serum and urine as a therapeutic guide in bacterial infections. J Infect Dis. 1974;129:187-93.

84. Kashuba ADM, Bertino JS, Nafziger AN. Dosing of aminoglycosides to rapidly attain pharmacodynamic goals and hasten therapeutic response by using individualized pharmacokinetic monitoring of patients with pneumonia caused by gram-negative organisms. Antimicrob Agents Chemother. 1998;42:1842-4.

85. Deziel-Evans LM, Murphy JE, Job ML. Correlation of pharmacokinetic indices with therapeutic outcome in patients receiving aminoglycosides. Clin Pharm. 1986;5:319-24.

86. Turnidge J. Pharmacodynamics and dosing of aminoglycosides. Infect Dis Clin N Am. 2003;17:503-28.

87. Hendlin D, Stapley EO, Jackson M, Wallick H, Miller AK, Wolf FJ, et al. Phosphonomycin, a new antibiotic produced by strains of streptomyces. Science. 1969;166:122-3.

88. Falagas ME, Vouloumanou EK, Samonis G, Vardakas KZ. Fosfomycin. Clin Microbiol Rev. 2016;29:321-47.

89. Silver LL. Fosfomycin: mechanism and resistance. Cold Spring Harb Perspect Med. 2017;7:1-12.

90. Kahan FM, Kahan JS, Cassidy PJ, Kropp H. The mechanism of action of fosfomycin (Phosphonomycin). Ann N Y Acad Sci. 1974;235:364-86.

91. Lemieux MJ, Huang Y, Wang DN. Glycerol-3-phosphate transporter of Escherichia coli: structure, function and regulation. Res Microbiol. 2004;155:623-9.

92. Winkler HH. Distribution of an inducible hexose-phosphate transport system among various bacteria. J Bacteriol. 1973;116:1079-81.

93. Gobernado M. Fosfomicina. Rev Esp Quimioter. 2003;16:15-40.

94. Scortti M, Lacharme-Lora L, Wagner M, Chico-Calero I, Losito P, Vázquez-Boland JA. Coexpression of virulence and fosfomycin susceptibility in Listeria: molecular basis of an antimicrobial in vitro-in vivo paradox. Nat Med. 2006;12:515-7.

95. Troxler R, von Graevenitz A, Funke G, Wiedemann B, Stock I. Natural antibiotic susceptibility of Listeria species: L. grayi, $L$. innocua, $L$. ivanovii, L. monocytogenes, $L$. seeligeri and $L$. welshimeri strains. Clin Microbiol Infect. 2000;6:525-35.

96. Alper MD, Ames BN. Transport of antibiotics and metabolite analogs by systems under cyclic AMP control: positive selection of Salmonella typhimurium cya and crp mutants. J Bacteriol. 1978;133:149-57.

97. Tsuruoka T, Miyata A, Yamada Y. Two kinds of mutants defective in multiple carbohydrate utilization isolated from in vitro fosfomycin-resistant strains of Escherichia coli K-12. J Antibiot (Tokyo). 1978;31:192-201.

98. Nilsson AI, Berg OG, Aspevall O, Kahlmeter G, Andersson DI. Biological costs and mechanisms of fosfomycin resistance in Escherichia coli. Antimicrob Agents Chemother. 2003;47:2850-8.

99. Kim DH, Lees WJ, Kempsell KE, Lane WS, Duncan K, Walsh CT. Characterization of a Cys 115 to Asp substitution in the Escherichia coli cell wall biosynthetic enzyme UDP-GlcNAc enolpyruvyl transferase (MurA) that confers resistance to inactivation by the antibiotic fosfomycin. Biochemistry. 1996:35:4923-8. 
100. Takahata S, Ida T, Hiraishi T, Sakakibara S, Maebashi K, Terada $\mathrm{S}$, et al. Molecular mechanisms of fosfomycin resistance in clinical isolates of Escherichia coli. Int J Antimicrob Agents. 2010;35:333-7.

101. Li Y, Zheng B, Li Y, Zhu S, Xue F, Liu J. Antimicrobial susceptibility and molecular mechanisms of fosfomycin resistance in clinical Escherichia coli isolates in mainland China. PLoS ONE. 2015;10:1-7.

102. Sorlozano-Puerto A, Lopez-Machado I, Albertuz-Crespo M, Martinez-Gonzalez LJ, Gutierrez-Fernandez J. Characterization of fosfomycin and nitrofurantoin resistance mechanisms in Escherichia coli isolated in clinical urine samples. Antibiotics. 2020;9:534.

103. Couce A, Briales A, Rodríguez-Rojas A, Costas C, Pascual Á, Blázquez J. Genomewide overexpression screen for fosfomycin resistance in Escherichia coli: MurA confers clinical resistance at low fitness cost. Antimicrob Agents Chemother. 2012;56:2767-9.

104. Arca P, Hardisson C, Suárez JE. Purification of a glutathione $\mathrm{S}$-transferase that mediates fosfomycin resistance in bacteria. Antimicrob Agents Chemother. 1990;34:844-8.

105. Suárez JE, Mendoza MC. Plasmid-encoded fosfomycin resistance. Antimicrob Agents Chemother. 1991;35:791-5.

106. Jiang Y, Shen P, Wei Z, Liu L, He F, Shi K, et al. Dissemination of a clone carrying a fosA3-harbouring plasmid mediates high fosfomycin resistance rate of KPC-producing Klebsiella pneumoniae in China. Int J Antimicrob Agents. 2015;45:66-70.

107. Sato N, Kawamura K, Nakane K, Wachino J-I, Arakawa Y. First detection of fosfomycin resistance Gene fosA3 in CTX-Mproducing Escherichia coli isolates from healthy individuals in Japan. Microb Drug Resist. 2013;19:477-82.

108. De Groote VN, Fauvart M, Kint CI, Verstraeten N, Jans A, Cornelis $\mathrm{P}$, et al. Pseudomonas aeruginosa fosfomycin resistance mechanisms affect non-inherited fluoroquinolone tolerance. J Med Microbiol. 2011;60:329-36.

109. Ito R, Mustapha MM, Tomich AD, Callaghan JD, McElheny CL, Mettus RT, et al. Widespread fosfomycin resistance in gramnegative bacteria attributable to the chromosomal fosA gene. MBio. 2017;8:1-9.

110. Zilhao R, Courvalin P. Nucleotide sequence of the fos $B$ gene conferring fosfomycin resistance in Staphylococcus epidermidis. FEMS Microbiol Lett. 1990;56:267-72.

111. Thompson MK, Keithly ME, Goodman MC, Hammer ND, Cook $\mathrm{PD}$, Jagessar KL, et al. Structure and function of the genomically encoded fosfomycin resistance enzyme, FosB, from Staphylococcus aureus. Biochemistry. 2014;53:755-65.

112. Fillgrove KL, Pakhomova S, Schaab MR, Newcomer ME, Armstrong RN. Structure and mechanism of the genomically encoded fosfomycin resistance protein, FosX, from Listeria monocytogenes. Biochemistry. 2007;46:8110-20.

113. Kuzuyama T, Kobayashi S, O'Hara K, Hidaka T, Seto H. Fosfomycin monophosphate and fosfomycin diphosphate, two inactivated fosfomycin derivatives formed by gene products of fom $A$ and fom $B$ from a fosfomycin producing organism Streptomyces wedmorensis. J Antibiot (Tokyo). 1996;49:502-4.

114. Schintler MV, Traunmuller F, Metzler J, Kreuzwirt G, Spendel $\mathrm{S}$, Mauric O, et al. High fosfomycin concentrations in bone and peripheral soft tissue in diabetic patients presenting with bacterial foot infection. J Antimicrob Chemother. 2009;64:574-8.

115. Joukhadar C. Target site penetration of fosfomycin in critically ill patients. J Antimicrob Chemother. 2003;51:1247-52.

116. Dijkmans AC, Zacarías NVO, Burggraaf J, Mouton JW, Wilms E, van Nieuwkoop C, et al. Fosfomycin: pharmacological clinical and future perspectives. Antibiotics. 2017;6:24.

117. Kirby WMM. Pharmacokinetics of Fosfomycin. Chemotherapy. 1977;23:141-51.
118. Pfausler B, Spiss H, Dittrich P, Zeitlinger M, Schmutzhard E, Joukhadar C. Concentrations of fosfomycin in the cerebrospinal fluid of neurointensive care patients with ventriculostomy-associated ventriculitis. J Antimicrob Chemother. 2004;53:848-52.

119. Kane Z, Gastine S, Obiero C, Williams P, Murunga S, Thitiri $\mathrm{J}$, et al. IV and oral fosfomycin pharmacokinetics in neonates with suspected clinical sepsis. J Antimicrob Chemother. 2021;76:1855-64.

120. Bergan T. Degree of absorption, pharmacokinetics of fosfomycin trometamol and duration of urinary antibacterial activity. Infection. 1990;18(Suppl 2):S65-9.

121. Bergan T, Thorsteinsson SB, Albini E. Pharmacokinetic profile of fosfomycin trometamol. Chemotherapy. 1993;39:297-301.

122. Bando T, Toyoshima H. Pharmacokinetics and clinical studies of fosfomycin in bile duct infections. Jpn J Antibiot. 1984;37:1279-88.

123. Molina MA, Olay T, Quero J. Pharmacodynamic data on fosfomycin in underweight infants during the neonatal period. Chemotherapy. 1977;23:217-22.

124. Guibert M, Magny JF, Poudenx F, Lebrun L, Dehan M. Comparative pharmacokinetics of fosfomycin in the neonate: 2 modes of administration. Pathol Biol (Paris). 1987;35:750-2.

125. Iarikov D, Wassel R, Farley J, Nambiar S. Adverse events associated with fosfomycin use: review of the literature and analyses of the FDA adverse event reporting system database. Infect Dis Ther. 2015;4:433-58.

126. Pericàs JM, Moreno $\mathrm{A}$, Almela $\mathrm{M}$, García-de-la-Mària $\mathrm{C}$, Marco $\mathrm{F}$, Muñoz $\mathrm{P}$ et al. Efficacy and safety of fosfomycin plus imipenem versus vancomycin for complicated bacteraemia and endocarditis due to methicillin-resistant Staphylococcus aureus: a randomized clinical trial. Clin Microbiol Infect. 2018;24:673-6.

127. Del Río A, Gasch O, Moreno A, Peña C, Cuquet J, Soy D, et al. Efficacy and safety of fosfomycin plus imipenem as rescue therapy for complicated bacteremia and endocarditis due to methicillin-resistant Staphylococcus aureus: a multicenter clinical trial. Clin Infect Dis. 2014;59:1105-12.

128. Li G, Standing JF, Bielicki J, Hope W, van den Anker J, Heath PT, et al. The potential role of fosfomycin in neonatal sepsis caused by multidrug-resistant bacteria. Drugs. 2017;77:941-50.

129. Ribes S, Taberner F, Domenech A, Cabellos C, Tubau F, Liñares $\mathrm{J}$, et al. Evaluation of fosfomycin alone and in combination with ceftriaxone or vancomycin in an experimental model of meningitis caused by two strains of cephalosporin-resistant Streptococcus pneumoniae. J Antimicrob Chemother. 2006;57:931-6.

130. Lepak AJ, Zhao M, Vanscoy B, Taylor DS, Ellis-Grosse E, Ambrose PG, et al. In vivo pharmacokinetics and pharmacodynamics of ZTI-01 (fosfomycin for injection) in the neutropenic murine thigh infection model against Escherichia coli, Klebsiella pneumoniae, and Pseudomonas aeruginosa. Antimicrob Agents Chemother. 2017;61:e00476-e517.

131. Walsh CC, McIntosh MP, Peleg AY, Kirkpatrick CM, Bergen PJ. In vitro pharmacodynamics of fosfomycin against clinical isolates of Pseudomonas aeruginosa. J Antimicrob Chemother. 2015;70:3042-50.

132. Grif K. In vitro activity of fosfomycin in combination with various antistaphylococcal substances. J Antimicrob Chemother. 2001;48:209-17.

133. Mazzei T, Cassetta MI, Fallani S, Arrigucci S, Novelli A. Pharmacokinetic and pharmacodynamic aspects of antimicrobial agents for the treatment of uncomplicated urinary tract infections. Int J Antimicrob Agents. 2006;28:35-41.

134. Docobo-Pérez F, Drusano GL, Johnson A, Goodwin J, Whalley $\mathrm{S}$, Ramos-Martín V, et al. Pharmacodynamics of fosfomycin: insights into clinical use for antimicrobial resistance. Antimicrob Agents Chemother. 2015;59:5602-10. 
135. Tsuji J, Satoh H, Narisada M, Hamashima Y, Yoshida T. Synthesis and antibacterial activity of 6315-S, a new member of the oxacephem antibiotic. J Antibiot. 1985;38:466-76.

136. Ito $\mathrm{M}$, Ishigami $\mathrm{T}$. The meaning of the development of flomoxef and clinical experience in Japan. Infection. 1991;19:253-7.

137. Bush K. Past and present perspectives on $\beta$-lactamases. Antimicrob Agents Chemother. 2018;62:e01076-e1118.

138. Bush K, Bradford PA. $\beta$-lactams and $\beta$-lactamase inhibitors: an overview. Cold Spring Harb Perspect Med. 2016;6:a025247.

139. Castanheira M, Deshpande LM, Mendes RE, Canton R, Sader HS, Jones RN. Variations in the occurrence of resistance phenotypes and carbapenemase genes among enterobacteriaceae isolates in 20 years of the SENTRY antimicrobial surveillance program. Open Forum Infect Dis. 2019;6:S23-33.

140. Yoshida T. Structural requirements for antibacterial activity and $\beta$-lactamase stability of $7 \beta$-arylmalonylamino- $7 \alpha$-methoxy-1oxacephems. Philos Trans R Soc Lond. 1980;237:231-7.

141. Neu HC, Aswapokee N. Antibacterial activity of a new 1-Oxa cephalosporin compared with that of other fl-lactam compounds. Antimicrob Agents Chemother. 1979;16:141-9.

142. Ruckdeschel G, Eder W. Comparative In vitro activity of the new oxacephem antibiotic, flomoxef (6315-S). Eur J Clin Microbiol Infect Dis. 1988;7:687-91.

143. Neu HC, Chin NX. In vitro activity and beta-lactamase stability of a new difluoro oxacephem, 6315-S. Antimicrob Agents Chemother. 1986;30:638-44.

144. Uchida K, Matsubara T. Effect of flomoxef on blood coagulation and alcohol metabolism. Infection. 1991;19:S284-95.

145. Andrassy K, Koderisch J, Gorges K, Sonntag H, Hirauchi K. Pharmacokinetics and hemostasis following administration of a new, injectable oxacephem (6315-S, flomoxef) in volunteers and in patients with renal insufficiency. Infection. 1991;19:S296-302.

146. Simon C, Simon M, Plieth C. In vitro activity of flomoxef in comparison to other cephalosporins. Infection. 1988;16:131-4.

147. Shah PM, Knothe H. The in vitro activity of flomoxef compared to four other cephalosporins and imipenem. Infection. 1991;19:279-83.

148. Yang Q, Zhang H, Cheng J, Xu Z, Xu Y, Cao B, et al. In vitro activity of flomoxef and comparators against Escherichia coli, Klebsiella pneumoniae and Proteus mirabilis producing extended-spectrum $\beta$-lactamases in China. Int $\mathbf{J}$ Antimicrob Agents. 2015;45:485-90.

149. Yang Q, Zhang H, Cheng J, Xu Z, Hou X, Xu Y. Flomoxef showed excellent in vitro activity against clinically important gram-positive and gram-negative pathogens causing communityand hospital-associated infections. Diagn Microbiol Infect Dis. 2015;81:269-74.

150. Jacoby GA, Carreras I. Activities of $\beta$-lactam antibiotics against Escherichia coli strains producing extended-spectrum $\beta$-lactamases. Antimicrob Agents Chemother. 1990;34:858-62.

151. Rodríguez-Baño J, Gutiérrez-Gutiérrez B, Machuca I, Pascual A. Treatment of infections caused by extended-spectrum-betalactamase-, AmpC-, and carbapenemase-producing enterobacteriaceae. Clin Microbiol Rev. 2018;31:1-42.

152. Lee CH, Liu JW, Li CC, Chien CC, Tang YF, Su LH. Spread of ISCR1 elements containing blaDHA-1 and multiple antimicrobial resistance genes leading to increase of flomoxef resistance in extended-spectrum- $\beta$-lactamase-producing Klebsiella pneumoniae. Antimicrob Agents Chemother. 2011;55:4058-63.

153. Cui L, Li Y, Lv Y, Xue F, Liu J. Antimicrobial resistance surveillance of flomoxef in China. J Infect Chemother. 2015;21:402-4.

154. Yang Q, Chen Y, Gu Y. In vitro antibacterial activity of oxacephems to clinical isolates producing extended-spectrum $\beta$-lactamases. Chinese J Infect Chemother. 2003;3:344-6.

155. Jung Y, Lee S, Song W, Kim H, Uh Y. In vitro activity of flomoxef against extended-spectrum $\beta$-lactamase-producing
Escherichia coli and Klebsiella pneumoniae in Korea. Diagn Microbiol Infect Dis. 2019;94:88-92.

156. Ngoi S, Teh C, Chong C, Abdul Jabar K, Tan S, Yu L, et al. In vitro efficacy of flomoxef against extended-spectrum beta-lactamase-producing Escherichia coli and Klebsiella pneumoniae associated with urinary tract infections in Malaysia. Antibiot. 2021;10:1-11.

157. Takesue Y, Kusachi S, Mikamo H, Sato J, Watanabe A, Kiyota $\mathrm{H}$, et al. Antimicrobial susceptibility of pathogens isolated from surgical site infections in Japan: comparison of data from nationwide surveillance studies conducted in 2010 and 2014-2015. J Infect Chemother. 2017;23:339-48.

158. Lee CH, Chen IL, Li CC, Chien CC. Clinical benefit of ertapenem compared to flomoxef for the treatment of cefotaximeresistant enterobacteriaceae bacteremia. Infect Drug Resist. 2018;11:257-66.

159. Matsumura Y, Yamamoto M, Nagao M, Komori T, Fujita N, Hayashi A, et al. Multicenter retrospective study of cefmetazole and flomoxef for treatment of extended-spectrum-beta-lactamase-producing escherichia. Antimicrob Agents Chemother. 2015;59:5107-13.

160. Lee CH, Su LH, Tang YF, Liu JW. Treatment of ESBL-producing Klebsiella pneumoniae bacteraemia with carbapenems or flomoxef: a retrospective study and laboratory analysis of the isolates. J Antimicrob Chemother. 2006;58:1074-7.

161. Murakami K, Nomura K, Doi M, Yoshida T. Production of lowaffinity penicillin-binding protein by low- and high-resistance groups of methicillin-resistant Staphylococcus. Antimicrob Agents Chemother. 1987;31:1307-11.

162. Sando M, Sato Y, Iwata S, Akita H, Sunakawa K. Protein binding ability of various antimicrobial drugs in neonates. Jpn J Chemother. 2004;52:568-73.

163. Okada T, Furukawa S. Clinical evaluation of flomoxef in pediatrics and a study on the penetration into cerebrospinal fluid. Jpn J Antibiot. 1987;40:1477-85.

164. Kumada T, Fukada T, Shimizu K, Koide K, Yamaguchi H. Preclinical and clinical evaluation of 6315-S (Flomoxef). Chemotherapy. 1987;35:632-7.

165. Nigam S, Bush K, Martovetsky G, Ahn S, Liu H, Richard E, et al. The organic anion transporter (OAT) family: a systems biology perspective. Physiol Rev. 2015;95:83-123.

166. Kimura $Y$, Nakashimizu H, Nakano M, Otsubo R, Matsubara $\mathrm{H}$, Yoshida T. Pharmacokinetic characterisation of 6315-S (flomoxef) in experimental animals. Chemotherapy. 1987;35:161-75.

167. Yasunaga K, Okamoto Y, Maehara K, Mase K, Iida Y, Yoshioka $\mathrm{S}$, et al. Phase-1 clinical study on 6315-S (Flomoxef). Chemotherapy. 1987;35:494-517.

168. Sato H, Narita A, Matsumoto K, Nakazawa S, Suzuki H, Nakanishi Y, et al. Studies of flomoxef in neonates. Jpn J Antibiot. 1991:44:1250-8.

169. Kimura K, Miyano T, Shimomura H. Pharmacokinetic studies of flomoxef in the neonatal field. Jpn J Antibiot. 1991;44:1303-6.

170. Fujii R, Fujita K, Murono K, Saijo M, Kakuya F, Yoshioka H, et al. Pharmacokinetics and clinical studies on flomoxef in neonates and premature infants. A study of flomoxef in the perinatal collaboration research group. Jpn J Antibiot. 1993;46:518-38.

171. Azagami S, Isohata E, Takeda S, Kin Y, Oikawa T, Osano M, et al. Pharmacokinetics and clinical efficacy of flomoxef in neonates. Jpn J Antibiot. 1991;44:1228-39.

172. Motohiro T, Maruoka T, Nagai K, Oki S, Tsumura N, Sasaki H, et al. Laboratory and clinical studies on flomoxef in neonates and premature infants. Jpn J Antibiot. 1993;46:547-67.

173. Okura K, Yamakawa M, Kuroki S, Haruta T, Kobayashi Y. Clinical evaluation of flomoxef in neonatal infections. Jpn J Antibiot. 1991;44:1286-93. 
174. Sakata H, Hirano Y, Maruyama S. Clinical efficacy of flomoxef in neonatal bacterial infection. Kansenshogaku Zasshi. 1993;67:212-7.

175. Fujita K, Murono K, Saijyo M, Kakuya F, Yoshioka H, Maruyama $\mathrm{S}$, et al. Flomoxef in neonates and young infants; clinical efficacy, pharmacokinetic evaluation and effect on the intestinal bacterial flora. Jpn J Antibiot Internet. 1991;44:1216-27.

176. Tabuki K, Nishimura T. Clinical studies on flomoxef in neonates. Jpn J Antibiot. 1993;46:539-46.

177. Akita H, Sato Y, Iwata S, Sunakawa K, Yokota T. Pharmacokinetic and clinical studies on flomoxef in neonates and premature infants. Jpn J Antibiot. 1991;44:1240-9.

178. Uri JV, Parks DB. Disulfiram-like reaction to certain cephalosporins. Ther Drug Monit. 1983;5:219-24.

179. Drummer S, Hauser WE, Remington JS. Antabuse-Like Effect of $\beta$-Lactam Antibiotics. N Engl J Med. 1980;303:1417-8.

180. Chen YC, Hung CC, Lin SF, Chang SC, Hsieh WC. Comparison of flomoxef with latamoxef in the treatment of sepsis and/ or gram-negative bacteremia in adult patients. Int J Antimicrob Agents. 1996;7:69-74

181. Wako Y, Hamauzu T, Tamura M, Yokote M, Yokote M, Shoji $\mathrm{S}$, et al. A case of flomoxef-induced pneumonitis. Nihon Kyobu Shikkan Gakkai Zasshi. 1992;30:643-7.

182. Ito A, Tatsumi Y, Wajima T, Nakamura R, Tsuji M. Evaluation of antibacterial activities of flomoxef against ESBL producing Enterobacteriaceae analyzed by monte carlo simulation. Jpn J Antibiot. 2013;66:71-86.

183. Craig WA. Pharmacokinetic/pharmacodynamic parameters: rationale for antibacterial dosing of mice and men. Clin Infect Dis. 1998;26:1-10.

184. Ito A, Tatsumi Y, Wajima T, Nakamura R, Tsuji M. Potent antibacterial activities of latamoxef (moxalactam) against ESBL producing Enterobacteriaceae analyzed by Monte Carlo simulation. Jpn J Antibiot. 2014;67:109-22.

185. Tashiro S, Hayashi M, Takemura W, Igarashi Y, Liu X, Mizukami Y, et al. Pharmacokinetics/pharmacodynamics evaluation of flomoxef against extended-spectrum beta-lactamase-producing Escherichia coli in vitro and in vivo in a murine thigh infection model. Pharm Res Pharmaceut Res. 2021;38:27-35.

186. Newton GG, Abraham EP. Isolation of cephalosporin C, a penicillin-like antibiotic containing D-alpha-aminoadipic acid. Biochem J. 1956;62:651-8.

187. Naito T, Aburaki S, Kamachi H, Narita Y, Okumura J, Kawaguchi $\mathrm{H}$. Synthesis and structure-activity relationships of a new series of cephalosporins, BMY-28142 and related compounds. J Antibiot (Tokyo). 1986;39:1092-107.

188. Grassi GG, Grassi C. Cefepime: Overview of activity in vitro and in vivo. J Antimicrob Chemother. 1993;32:87-94.

189. Nikaido H, Liu W, Rosenberg EY. Outer membrane permeability and $\beta$-lactamase stability of dipolar ionic cephalosporins containing methoxyimino substituents. Antimicrob Agents Chemother. 1990;34:337-42.

190. Pucci MJ, Boice-Sowek J, Kessler RE, Dougherty TJ. Comparison of cefepime, cefpirome, and cefaclidine binding affinities for penicillin-binding proteins in Escherichia coli K-12 and Pseudomonas aeruginosa SC8329. Antimicrob Agents Chemother. 1991;35:2312-7.

191. Kessler RE, Bies M, Buck RE, Chisholm DR, Pursiano TA, Tsai $\mathrm{YH}$, et al. Comparison of a new cephalosporin, BMY 28142, with other broad-spectrum $\beta$-lactam antibiotics. Antimicrob Agents Chemother. 1985;27:207-16.

192. Sanders CC. Cefepime: the next generation? Clin Infect Dis. 1993;17:369-79.

193. Queenan AM, Shang W, Kania M, Page MGP, Bush K. Interactions of ceftobiprole with $\beta$-lactamases from molecular classes A to D. Antimicrob Agents Chemother. 2007;51:3089-95.
194. Hiraoka M, Masuyoshi S, Mitsuhashi S, Tomatsu K, Inoue M. Cephalosporinase interactions and antimicrobial activity of BMY-28142, ceftazidime and cefotaxime. J Antibiot (Tokyo). 1988;41:86-93.

195. Queenan AM, Foleno B, Gownley C, Wira E, Bush K. Effects of inoculum and beta-lactamase activity in AmpC- and extendedspectrum beta-lactamase (ESBL)-producing Escherichia coli and Klebsiella pneumoniae clinical isolates tested by using NCCLS ESBL methodology. J Clin Microbiol. 2004;42:269-75.

196. Kang CI, Pai H, Kim SH, Kim HB, Kim EC, Oh MD, et al. Cefepime and the inoculum effect in tests with Klebsiella pneumoniae producing plasmid-mediated AmpC-type $\beta$-lactamase. J Antimicrob Chemother. 2004;54:1130-3.

197. Coudron PE, Hanson ND, Climo MW. Occurrence of extendedspectrum and ampC beta-lactamases in bloodstream isolates of Klebsiella pneumoniae: Isolates harbor plasmid-mediated FOX-5 and ACT-1 AmpC beta-lactamases. J Clin Microbiol. 2003;41:772-7.

198. Tärnberg M, Östholm-Balkhed $\AA$, Monstein HJ, Hällgren A, Hanberger $\mathrm{H}$, Nilsson LE. In vitro activity of beta-lactam antibiotics against CTX-M-producing Escherichia coli. Eur J Clin Microbiol Infect Dis. 2011;30:981-7.

199. Paterson DL, Ko WC, Von Gottberg A, Casellas JM, Mulazimoglu L, Klugman KP, et al. Outcome of cephalosporin treatment for serious infections due to apparently susceptible organisms producing extended-spectrum $\beta$-lactamases: Implications for the clinical microbiology laboratory. J Clin Microbiol. 2001;39:2206-12.

200. Kotapati S, Kuti JL, Nightingale CH, Nicolau DP. Clinical implications of extended spectrum $\beta$-lactamase (ESBL) producing Klebsiella species and Escherichia coli on cefepime effectiveness. J Infect. 2005;51:211-7.

201. Germel C, Haag A, Söderquist B. In vitro activity of beta-lactam antibiotics to community-associated methicillin-resistant Staphylococcus aureus (CA-MRSA). Eur J Clin Microbiol Infect Dis. 2012;31:475-80.

202. Nikaido H. Outer membrane barrier as a mechanism of antimicrobial resistance. Antimicrob Agents Chemother. 1989;33:1831-6.

203. Chen HY, Livermore DM. Activity of cefepime and other betalactam antibiotics against permeability mutants of Escherichia coli and Klebsiella pneumoniae. J Antimicrob Chemother. 1993;32(Suppl B):63-74.

204. James CE, Mahendran KR, Molitor A, Bolla JM, Bessonov AN, Winterhalter $\mathrm{M}$, et al. How $\beta$-lactam antibiotics enter bacteria: a dialogue with the porins. PLoS ONE. 2009;4:5453.

205. Ong CT, Tessier PR, Li C, Nightingale CH, Nicolau DP. Comparative in vivo efficacy of meropenem, imipenem, and cefepime against Pseudomonas aeruginosa expressing MexA-MexB-OprM efflux pumps. Diagn Microbiol Infect Dis. 2007;57:153-61.

206. Campo Esquisabel AB, Rodríguez MC, Campo-Sosa AO, Rodríguez C, Martínez-Martínez L. Mechanisms of resistance in clinical isolates of Pseudomonas aeruginosa less susceptible to cefepime than to ceftazidime. Clin Microbiol Infect. 2011;17:1817-22.

207. Van der Auwera P, Santella PJ. Pharmacokinetics of cefepime: a review. J Antimicrob Chemother. 1993;32(Suppl B):103-15.

208. Barbhaiya RH, Forgue ST, Gleason CR, Knupp CA, Pittman KA, Weidler DJ, et al. Safety, tolerance, and pharmacokinetic evaluation of cefepime after administration of single intravenous doses. Antimicrob Agents Chemother. 1990;34:1118-22.

209. Barbhaiya RH, Forgue ST, Shyu WC, Papp EA, Pittman KA. High-pressure liquid chromatographic analysis of BMY-28142 in plasma and urine. Antimicrob Agents Chemother. 1987;31:55-9.

210. Lima-Rogel V, Medina-Rojas EL, Milan-Segovia RC, Noyola DE, Nieto-Aguirre K, López-Delarosa A, et al. Population 
pharmacokinetics of cefepime in neonates with severe nosocomial infections. J Clin Pharm Ther. 2008;33:295-306.

211. Capparelli E, Hochwald C, Rasmussen M, Parham A, Bradley J, Moya F. Population pharmacokinetics of cefepime in the neonate. Antimicrob Agents Chemother. 2005;49:2760-6.

212. Kavi J, Andrews JM, Ashby JP, Hillman G, Wise R. Pharmacokinetics and tissue penetration of cefpirome, a new cephalosporin. J Antimicrob Chemother. 1988;22:911-6.

213. Nye KJ, Shi YG, Andrews JM, Wise R. Pharmacokinetics and tissue penetration of cefepime. J Antimicrob Chemother. 1989;24:23-8.

214. Barbhaiya RH, Forgue ST, Gleason CR, Knupp CA, Pittman KA, Weidler DJ, et al. Pharmacokinetics of cefepime after single and multiple intravenous administrations in healthy subjects. Antimicrob Agents Chemother. 1992;36:552-7.

215. Rhoney DH, Tam VH, Parker D, McKinnon PS, Coplin WM. Disposition of cefepime in the central nervous system of patients with external ventricular drains. Pharmacotherapy. 2003;23:310-4.

216. Ellis JM, Rivera L, Reyes G, Castillo F, Marte P, Tejada M, et al. Cefepime cerebrospinal fluid concentrations in neonatal bacterial meningitis. Ann Pharmacother. 2007;41:900-1.

217. Barbhaiya RH, Knupp CA, Forgue ST, Matzke GR, Halstenson CE, Opsahl JA, et al. Disposition of the cephalosporin cefepime in normal and renally impaired subjects. Drug Metab Dispos. 1991;19:68-73

218. Ganapathy ME, Huang W, Rajan DP, Carter AL, Sugawara $\mathrm{M}$, Iseki $\mathrm{K}$, et al. $\beta$-Lactam antibiotics as substrates for OCTN2, an organic cation/carnitine transporter. J Biol Chem. 2000;275:1699-707.

219. Bretschneider B, Brandsch M, Neubert R. Intestinal transport of $\beta$-lactam antibiotics: analysis of the affinity at the $\mathrm{H}+/$ peptide symporter (PEPT1), the uptake into Caco-2 cell monolayers and the transepithelial flux. Pharm Res. 1999;16:55-61.

220. Craig WA. Interrelationship between pharmacokinetics and pharmacodynamics in determining dosage regimens for broad-spectrum cephalosporins. Diagn Microbiol Infect Dis. 1995;22:89-96.

221. Oster S, Edelstein H, Cassano K, McCabe R. Open trial of cefepime (BMY 28142) for infections in hospitalized patients. Antimicrob Agents Chemother. 1990;34:954-7.

222. Edelstein H, Chirurgi V, Oster S, Karp R, Cassano K, Aiken S, et al. A randomized trial of cefepime (BMY-28142) and ceftazidime for the treatment of pneumonia. J Antimicrob Chemother. 1991;28:569-75.

223. Payne LE, Gagnon DJ, Riker RR, Seder DB, Glisic EK, Morris JG, et al. Cefepime-induced neurotoxicity: a systematic review. Crit Care. 2017;21:276.

224. Durand-Maugard C, Lemaire-Hurtel AS, Gras-Champel V, Hary L, Maizel J, Prud'homme-Bernardy A, et al. Blood and
CSF monitoring of cefepime-induced neurotoxicity: nine case reports. J Antimicrob Chemother. 2012;67:1297-9.

225. Sugimoto M, Uchida I, Mashimo T, Yamazaki S, Hatano K, Ikeda F, et al. Evidence for the involvement of GABA(A) receptor blockade in convulsions induced by cephalosporins. Neuropharmacology. 2003;45:304-14.

226. Paul M, Yahav D, Fraser A, Leibovici L. Empirical antibiotic monotherapy for febrile neutropenia: systematic review and meta-analysis of randomized controlled trials. J Antimicrob Chemother. 2006;57:176-89.

227. Yahav D, Paul M, Fraser A, Sarid N, Leibovici L. Efficacy and safety of cefepime: a systematic review and meta-analysis. Lancet Infect Dis. 2007;7:338-48.

228. Kim PW, Wu Y, Cooper C, Rochester G, Valappil T, Wang Y, et al. Meta-analysis of a possible signal of increased mortality associated with cefepime use. Clin Infect Dis. 2010;51:381-9.

229. Adderson EE, Flynn PM, Hoffman JM. Efficacy and safety of cefepime in pediatric patients: a systematic review and metaanalysis. J Pediatr. 2010;157:490-5. https://doi.org/10.1016/j. jpeds.2010.03.023.

230. Arnold CJ, Ericson J, Cho N, Tian J, Wilson S, Chu VH, et al. Cefepime and ceftazidime safety in hospitalized infants. Pediatr Infect Dis J. 2015;34:964-8.

231. Knoderer CA, Kaylor DM, Toth ME, Malloy KM, Nichols KR. Characterization of the clinical outcomes with cefepime in a neonatal intensive care unit: a retrospective cohort study. J Pediatr Pharmacol Ther. 2018;23:209-14.

232. Hoffman JM, Frediani J, Herr M, Flynn PM, Adderson EE. The safety of cefepime and ceftazidime in pediatric oncology patients. Pediatr Blood Cancer. 2013;60:806-9.

233. Sullins AK, Abdel-Rahman SM. Pharmacokinetics of antibacterial agents in the CSF of children and adolescents. Pediatr Drugs. 2013;15:93-117.

234. Denis F, Cadoz M, Mounier M, Prince-David M, M'Boup S, Diouf $\mathrm{O}$, et al. Spinal concentrations of amoxicillin in purulent meningitis in children. Pathol Biol (Paris). 1983;31:308-10.

235. NeoAMR Observational Study in Neonatal SepsisNCT03721302. ClinicalTrials.gov. 2018. https://clinicaltrials. gov/ct2/show/NCT03721302. Cited 5 Jun 2020.

236. Alpern JD, Zhang L, Stauffer WM, Kesslheim AS. Trends in pricing and generic competition within the oral antibiotic drug market in the United States. Clin Infect Dis. 2017;65:1848-52.

237. Joint Formulary Committee. British National Formulary (online). BMJ Gr Pharm Press. 2021. https://about.medicinescomplete. com/publication/british-national-formulary/

238. Chinese import and purchase price data of flomoxef. https://db. yaozh.com/yaopinzhongbiao?comprehensivesearchcontent= flomoxef. Cited 7 Jul 2021 